Article

\title{
Novel Sequence Features of DNA Repair Genes/Proteins from Deinococcus Species Implicated in Protection from Oxidatively Generated Damage
}

\author{
F. M. Nazmul Hassan and Radhey S. Gupta * \\ Department of Biochemistry and Biomedical Sciences, McMaster University, Hamilton, ON L8N 3Z5, Canada; \\ hassaf5@mcmaster.ca \\ * Correspondence: gupta@mcmaster.ca; Tel.: +1-905-525-9140
}

Received: 1 February 2018; Accepted: 27 February 2018; Published: 8 March 2018

\begin{abstract}
Deinococcus species display a high degree of resistance to radiation and desiccation due to their ability to protect critical proteome from oxidatively generated damage; however, the underlying mechanisms are not understood. Comparative analysis of DNA repair proteins reported here has identified 22 conserved signature indels (CSIs) in the proteins UvrA1, UvrC, UvrD, UvsE, MutY, MutM, Nth, RecA, RecD, RecG, RecQ, RecR, RuvC, RadA, PolA, DnaE, LigA, GyrA and GyrB, that are uniquely shared by all/most Deinococcus homologs. Of these CSIs, a 30 amino acid surface-exposed insert in the Deinococcus UvrA1, which distinguishes it from all other UvrA homologs, is of much interest. The uvrA1 gene in Deinococcus also exhibits specific genetic linkage (predicted operonic arrangement) to genes for three other proteins including a novel Deinococcus-specific transmembrane protein (designated dCSP-1) and the proteins DsbA and DsbB, playing central roles in protein disulfide bond formation by oxidation-reduction of CXXC ( $C$ represents cysteine, $X$ any other amino acid) motifs. The CXXC motifs provide important targets for oxidation damage and they are present in many DNA repair proteins including five in UvrA, which are part of Zinc-finger elements. A conserved insert specific for Deinococcus is also present in the DsbA protein. Additionally, the $u v s E$ gene in Deinococcus also shows specific linkage to the gene for a membrane-associated protein. To account for these novel observations, a model is proposed where specific interaction of the Deinococcus UvrA1 protein with membrane-bound dCSP-1 enables the UvrA1 to receive electrons from DsbA-DsbB oxido-reductase machinery to ameliorate oxidation damage in the UvrA1 protein.
\end{abstract}

Keywords: Deinococcus species; radiation and desiccation resistance; conserved signature indels; oxidatively generated damage; CXXC motifs in protein sequences; DsbA proteins; DsbB proteins; UvrA1 proteins; UvsE proteins

\section{Introduction}

Members of the genus Deinococcus, which are part of the phylum Deinococcus-Thermus [1-6] are characterized by their extraordinary tolerance to ionizing radiation (IR), ultraviolet radiation (UV) and desiccating conditions [7-10]. Due to their high level of resistance to radiation and desiccation, which are lethal or growth inhibitory to most other organisms, Deinococcus species have been extensively studied for understanding the biochemical mechanisms responsible for their resistance characteristics [7,9,11-18]. Earlier work shows that radiation (ionizing or UV) or desiccating conditions produce comparable DNA damage in Deinococcus species as in sensitive organisms (e.g., Escherichia coli) but in contrast to the sensitive organisms, damaged DNA in Deinococcus species gets efficiently repaired leading to their observed resistance phenotype $[9,11,12,14,19,20]$. Similar to other prokaryotic organisms, Deinococcus species possess classical DNA repair machinery consisting of the base excision repair (BER), nucleotide excision repair (NER), mismatch repair (MMR) and double-strand break 
(DSB) repair pathways $[11,12,16,21]$. Most of the proteins in these pathways are conserved and thus far very few novel aspects of these proteins or DNA repair pathways have been identified that could account for the highly efficient mode of DNA repair in Deinococcus species $[11,12,16,21]$. The genomes of Deinococcus species also contain a number of proteins which are specific for this group of bacteria [21,22] and the genes for some of them (e.g., DdrA, DdrB, DdrD, PprA) are induced upon radiation or desiccation exposure $[23,24]$, suggesting that they play important roles in DNA damage response $[11,12,14,23]$. However, our current understanding of the cellular functions of these proteins, or other proteins involved in DNA repair processes, does not satisfactorily account for the efficient repair of DNA observed in Deinococcus species [11,12,25-27].

The detrimental effects of radiation or desiccation on living organisms, including DNA damage and strand breaks, are mainly produced by oxidatively generated damage caused by reactive oxygen species (ROS) $[9,12,14,19,20,28,29]$. However, the damaging effects of ROS are not limited to DNA but oxidation and inactivation of proteins are also important consequences [12,14,20,29-31]. An important observation in this context is that while DNA from both radiation-sensitive and -resistant organisms is equally susceptible to radiation or desiccation-induced damage, there is much less damage of the proteome in resistant organisms such as Deinococcus in comparison to sensitive organisms $[9,12,14,19,20]$. This observation indicates that the ability of Deinococcus species to withstand the effects of high doses of radiation and other ROS-inducing conditions is in large part due to their unique ability to protect their proteome from oxidatively generated damage $[9,12,14,20]$. Although Deinococcus species contain several proteins involved in antioxidant defense including thioredoxin, glutaredoxin, thioredoxin reductase, glutathione, glutathione reductase, etc., their presence is not unique to these bacteria [12]. However, recent studies show that Deinococcus species contain much higher intracellular concentration of $\mathrm{Mn}^{+2}$ and $\mathrm{Mn}^{+2}$-phosphate complexes, which are potent scavengers of superoxide radicals, suggesting that the high $\mathrm{Mn}^{+2} / \mathrm{Fe}^{+2}$ ratio in these organisms could provide protection from oxidative stress $[12,14,20,32-35]$. While the role played by high $\mathrm{Mn}^{+2} / \mathrm{Fe}^{+2}$ concentrations in protecting from oxidative stress is of importance, it does not explain the selective protection of proteome (as compared to DNA) in Deinococcus species. Thus, it is possible that in addition to the role played by $\mathrm{Mn}^{+2}$ complexes and other small molecules, proteins involved in DNA repair processes from Deinococcus species may contain certain novel molecular attributes that protect them from oxidatively generated damage. However, thus far no unique features in DNA repair proteins from Deinococcus have been identified.

Our comparative genomic analyses on members of the phylum Deinococcus-Thermus have identified large numbers of novel sequence features that are specific for the Deinococcus species $[5,22,36]$. These novel sequence characteristics include several conserved signature indels (CSIs) in important proteins of Deinococcus species as well as more than 28 conserved signature proteins (CSPs), whose homologs are only present in all/most Deinococcus species [5,22]. Earlier work on CSIs shows that they are generally present on protein surfaces and mediate novel protein-protein or protein-DNA interactions, which are important for the CSI-containing organisms [37-40]. Similarly, the CSPs found only in a given group of organisms, are also predicted to play important cellular functions in these organisms [41-43]. A number of such proteins (viz. DdrB, PprA), which are specifically found in species from either the genus Deinococcus or the order Deinococcales have been extensively studied and are known to play important role in the DNA repair process $[26,27,44-46]$. In view of the important roles that CSIs and CSPs play in conferring novel cellular functions, the present study was undertaken to identify CSIs which are specifically found in the DNA repair proteins from Deinococccus species. Results of these studies have identified 22 CSIs in many important DNA repair proteins from different pathways. Of the identified CSIs, one CSI of much interest consists of a 30 amino acid insert uniquely found in all of the UvrA1 homologs from Deinococcus species. The UvrA1 protein, which is part of the nucleotide excision repair (NER) pathway [12,47], plays a central role in the DNA repair process due to its ability to initially recognize a broad range of DNA damages including cyclobutane pyrimidine dimers and 6,4-photoproducts formed by UV light and multiple other types of 
damaged nucleotides/bases resulting from exposure to ionizing radiation [11,12,47-49]. Subsequently, other proteins in the NER pathway viz. UvrB and UvrC excise the damaged region and the gap created is filled by DNA polymerase I and ligated by DNA ligase [11,12,47-49]. Our studies show that the gene for UvrA1 in Deinococcus species exhibits a novel genetic organization (i.e., operonic arrangement) with the genes for a Deinococcus-specific CSP (dCSP-1, predicted to be a transmembrane protein) and two other membrane-associated proteins (DsbA and DsbB), which are known to play central roles in disulfide bond formation in proteins by oxidation-reduction of cysteine residues in CXXC motifs [50-52]. Our analysis shows that many DNA repair proteins contain surface exposed CXXC motifs, which are highly susceptible to oxidation damage $[30,53,54]$ and of these UvrA protein contains 5 CXXC motifs, which are part of three zinc-finger elements commonly utilized by proteins for recognizing either specific regions in DNA or for mediating protein-protein interactions [47,54-56]. Additionally, our results also reveal that the UvsE protein, central to the UvsE-dependent pathway of excision DNA repair [49], also contains a 1 amino acid CSI specific for Deinococcus homologs and the gene for this protein exhibits a novel genetic linkage with the gene for a predicted transmembrane protein. The significances of these findings as well as a number of other novel observations on DNA repair proteins from Deinococcus species regarding their ability to protect their DNA repair machinery from oxidatively generated damage are discussed.

\section{Materials and Methods}

\subsection{Identification of CSIs in DNA Repair Proteins}

Identification of conserved signature indels in DNA repair proteins was carried out as described in our earlier work [5,57]. In brief, BLASTp [58] searches were conducted on different DNA repair proteins from the genome of Deinococcus radiodurans R1 [59] to retrieve homologs from different members of the Deinococcus-Thermus phylum and representative members from other groups of bacteria. Multiple sequence alignments of different proteins were created using ClustalX [60]. The alignments were visually inspected to identify any conserved insertion or deletion, which was specific for members of the genus Deinococcus and which was flanked on both sides by at least 5-6 conserved amino acids in the neighboring 30-40 amino acids. The specificities of these indels for Deinococcus species were evaluated by performing additional BLASTp searches on short sequence segments containing the insertions or deletions and their flanking conserved regions (60-100 amino acids long). SIG_CREATE and SIG_STYLE (available on Gleans.net) were then used to create the formatted signature files showing the presence of CSIs in the sequence alignments [57]. Although sequence information is shown for only a limited number of species in these alignments, unless otherwise indicated, all of the CSIs shown here are specific for the Deinococcus species and similar CSIs were not detected in any other organism in the top 250 BLAST hits analyzed.

\subsection{Protein-Protein Interactions (PPIs) and Genetic Neighborhood Analyses}

The STRING database was initially used to determine any unique association observed for the DNA repair proteins from Deinococcus species. The STRING database contains information regarding protein-protein interactions (PPIs) based on experimental data and it also predicts interactions based on co-occurrence of the proteins, gene fusion data, co-expression of the proteins and genetic neighborhood analysis $[61,62]$. More detailed genetic-linkage analysis on the genes for selected proteins (e.g., UvrA1 and UvsE) was carried out by examining the position of a given gene and its neighboring genes from the graphic views of the genomes. Intergenic distances and the direction of transcription for different genes were also determined based on the genome sequences.

\subsection{Homology Modeling of the Uvra1 Protein and Other Proteins from Deinococcus Species}

Three-dimensional structure models of the UvrA1, UvrC and UvsE proteins from D. radiodurans were developed from the full-length sequences of these proteins using the homology modeling 
technique [63]. The secondary structure analysis on the sequences of these proteins from $D$. radiodurans was initially performed via PSIPRED v3.3 web server [64]. Suitable templates for homology modeling were identified by using PSI-Blast search [58] against the Protein Data Bank (PDB) [65]. The templates used for construction of homology models of the UvrA, UvrC and UvsE proteins of D. radiodurans were based on the following structures; UvrA1, Geobacillus sp. Y412MC52 (PDB id: 3UWX) [66]; UvrC, Thermotoga maritime (PDB id: 2NRT) [67]; and UvsE, Sulfolobus acidocaldarius (PDB id: 3TC3) [68]. Based on these template structures, 200 models were initially generated using Modeller v9.14 [63] and ranked using discrete optimized protein energy (DOPE) potential scores [69]. The ModRefiner program was then used for the refinement of selected models [70]. The secondary structure elements in the regions containing CSIs were examined and compared with results of the PSIPRED analysis to ensure their reliability. The assessment of the final structure models was conducted using five independent servers: PROSA [71,72], RAMPAGE [73], ERRAT [74], Verify3D [75] and QMEAN [76]. All the modeled structures were visualized and analyzed using the molecular visualization program PyMol (http: / / www.pymol.org).

\section{Results}

\subsection{Conserved Signature Indels in DNA Repair Proteins Specific for the Deinococcus Species}

To explore whether the proteins involved in DNA repair pathways in Deinococcus species contain any unique sequence features differentiating them from homologs found in other prokaryotic organisms, multiple sequence alignments of various DNA repair proteins from Deinococcus and other representative groups of bacteria were created. These alignments were examined for the presence of any conserved signature indels (CSIs) that are specifically found in the Deinococcus homologs [5,36-57]. These analyses have identified 22 novel CSIs in 20 different DNA repair related proteins which, except for an isolated exception, are uniquely found in the Deinococcus homologs. A summary of the identified Deinococcus-specific CSIs in different DNA repair proteins is provided in Table 1. Of these CSIs, two CSIs in the DNA repair protein RadA, one of which is specific for the Deinococcus-Thermus phylum and the other for the order Deinococcales, were described in our recent work [5]. As seen from Table 1, the CSIs distinguishing the Deinococcus homologs from other bacteria are present in large numbers of DNA repair proteins that are part of different pathways [11,12]. The proteins containing the CSIs include UvrA1 and UvrC from the NER pathway [18,47]; UvsE protein from the UV damage endonuclease-dependent excision repair (UVER) pathway [49-77]; MutY, MutM and Nth proteins from the base-excision repair (BER) pathway [11,12]; $\operatorname{Rec} A, \operatorname{RecD}, \operatorname{RecG}, \operatorname{Rec} Q, \operatorname{RecR}, \operatorname{RuvC}$ and $\operatorname{RadA}$ proteins from the homologous recombination (HR) pathway [11,12] and the proteins PolA, DnaE, LigA, UvrD, GyrA and GyrB which play central roles in multiple DNA repair pathways [11,12].

Table 1. Summary of the Deinococcus-specific Conserved Signature Indels (CSIs) in DNA Repair Proteins.

\begin{tabular}{|c|c|c|c|c|c|}
\hline Protein Name & Repair Pathway & Protein ID $^{a}$ & Indel Size & Indel $^{b}$ Position & Figure \\
\hline UvrA1 & NER & DR1771 & 30 aa ins & $421-514$ & Figure $1 \mathrm{~A}$ \\
\hline UvrC & NER & DR1354 & 16 aa ins & $459-535$ & Figure 1B \\
\hline UvrD & MP & DR1775 & 6 aa ins & $516-576$ & Figure $2 \mathrm{~A}$ \\
\hline UvsE & UVER & DR1819 & 1 aa ins & $48-125$ & Figure 2B \\
\hline MutY & BER & DR2285 & 4 aa ins & $24-82$ & Figure S1 \\
\hline MutM & BER & DR0493 & 2 aa del & $168-225$ & Figure S2 \\
\hline Endonuclease III (Nth) & BER & DR0928 & 2 aa ins & $144-228$ & Figure S3 \\
\hline $\operatorname{Rec}^{c}$ & HR & DR2340 & 1 aa ins & $216-280$ & Figure S4 \\
\hline $\operatorname{RecR}^{c}$ & HR & DR0198 & 2 aa del & $104-164$ & Figure S5 \\
\hline DNA helicase (RecQ) & $\mathrm{HR}$ & DR1289 & 2 aa del & $453-510$ & Figure S6 \\
\hline Helicase RecD protein & HR & DR1902 & 2 aa del & $376-427$ & Figure S7A \\
\hline Helicase RecD protein & HR & DR1902 & 2 aa del & $426-493$ & Figure S7B \\
\hline RuvC protein & HR & DR0440 & 2 aa del & $82-147$ & Figure S8 \\
\hline DNA helicase RecG protein & HR & DR1916 & 1 aa ins & $14-73$ & Figure S9 \\
\hline
\end{tabular}


Table 1. Cont.

\begin{tabular}{|c|c|c|c|c|c|}
\hline Protein Name & Repair Pathway & Protein ID ${ }^{a}$ & Indel Size & Indel ${ }^{b}$ Position & Figure \\
\hline \multirow{2}{*}{ DNA Repair protein RadA } & \multirow{2}{*}{ HR } & \multirow{2}{*}{ DR1105 } & 1 aa del; ${ }^{c}$ & 175-195 & \multirow{2}{*}{ [5] } \\
\hline & & & 2 aa del & $225-257$ & \\
\hline DNA polymerase I (PolA) & MP & DR1707 & 2 aa ins & $191-257$ & Figure S10 \\
\hline DNA polymerase III, $\alpha$ subunit (DnaE) & MP & DR0507 & 65 aa ins & $315-491$ & Figure S11 \\
\hline DNA polymerase III, $\alpha$ subunit (DnaE) & MP & DR0507 & 2 aa ins & $75-131$ & Figure S12 \\
\hline DNA ligase (LigA) & MP & DR2069 & 3 aa ins & $101-169$ & Figure S13 \\
\hline Gyrase A (GyrA) & MP & DR1913 & 1 aa ins & $265-341$ & Figure S14 \\
\hline Gyrase B (GyrB) & $\mathrm{MP}$ & DR0906 & 1 aa ins & 27-99 & Figure S15 \\
\hline
\end{tabular}

a Protein ID corresponds to the Deinococcus radiodurans genome; ${ }^{\mathbf{b}}$ The indel position indicates the region of the protein where the CSI is found. Ins and del indicate whether the CSI is an insertion or a deletion; ${ }^{\mathbf{c}}$ Indel is specific for Deinococcus-Thermus phylum; Abbreviations: BER- Base excision repair; NER-Nucleotide excision repair; HRHomologous recombination; UVER-UV damage endonuclease (UvsE)-dependent excision repair; MR- Mismatch repair; MP-Multiple pathways. The CSIs in RadA were identified in earlier work [5].

Of the identified CSIs, sequence information for two prominent conserved inserts found in the proteins UvrA1 and UvrC is provided in Figure 1. As seen from Figure 1A, the UvrA1 protein from Deinococcus contains a 30 amino acid insertion within a conserved region that is uniquely shared by all Deinococcus species. The UvrA homologs from other groups of bacteria as well as the UvrA2 homologs from Deinococcus species lack this large insert, indicating that this insert is specific for the UvrA1 homologs. Although a shorter insert in this position is present in the Meiothermus species, this insert shows minimal sequence similarity to the insert in the Deinococcus homologs indicating that it has very likely originated independently. In addition to the UvrA1 protein, UvrC protein from Deinococcus species also contains a 16 amino acid insertion in a conserved region that distinguishes the Deinococcus homologs from the UvrC homologs in all other bacteria (Figure 1B). Sequence information for two other Deinococcus-specific CSIs found in the UvrD and UvsE proteins are presented in Figure 2. Sequence information for the remainder of the Deinococcus-specific CSIs in DNA repair proteins identified in this work is provided in Figures S1-S15. Although sequence information for different CSIs is shown here for a limited number of species, unless indicated otherwise, these CSIs are specifically present in all genome-sequenced Deinococcus species. Due to the specificities of these CSIs for the Deinococcus species, the genetic changes responsible for most of these CSIs likely occurred in a common ancestor of the genus Deinococcus. 

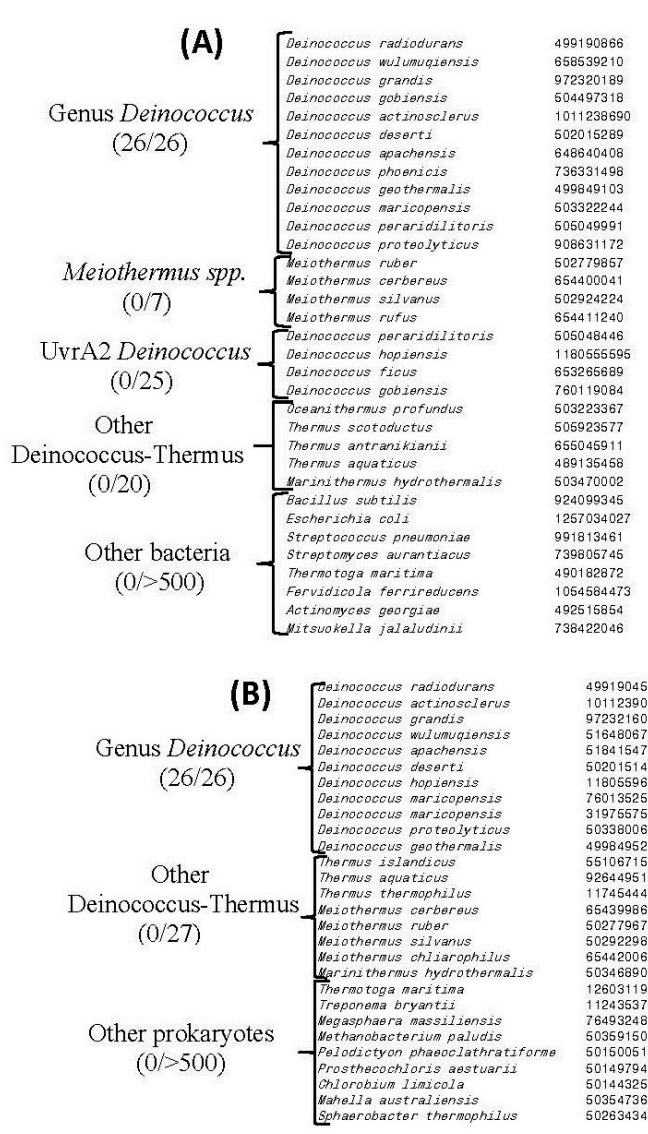
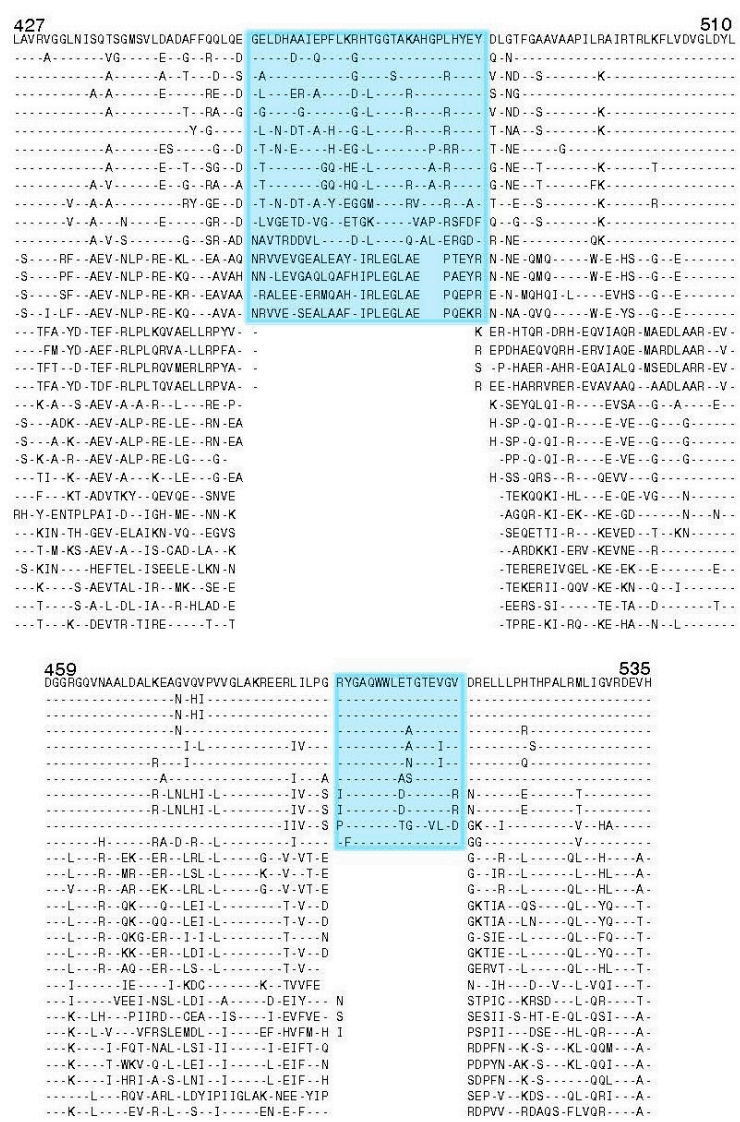

Figure 1. Conserved signature indels in the UvrA1 and UvrC proteins that are specific for the Deinococcus homologs. (A) Partial sequence alignment of the UvrA protein showing a 30 amino acid insertion in a conserved region that is uniquely shared by the UvrA1 homologs from all 26 genome-sequenced Deinococcus species including Deinococcus aerius. This insert is not shared by the UvrA2 homologs of Deinococcus spp. but a shorter unrelated insert in this position is present in Meiothermus spp.; (B) Excerpts from the sequence alignment of UvrC protein showing a 16 amino acid insertion that is specific for Deinococcus homologs. The dashes (-) in these as well as other sequence alignments indicate identity with the amino acid present on the top line. The numbers on the top indicate the location of the sequence in the Deinococcus radiodurans protein. 

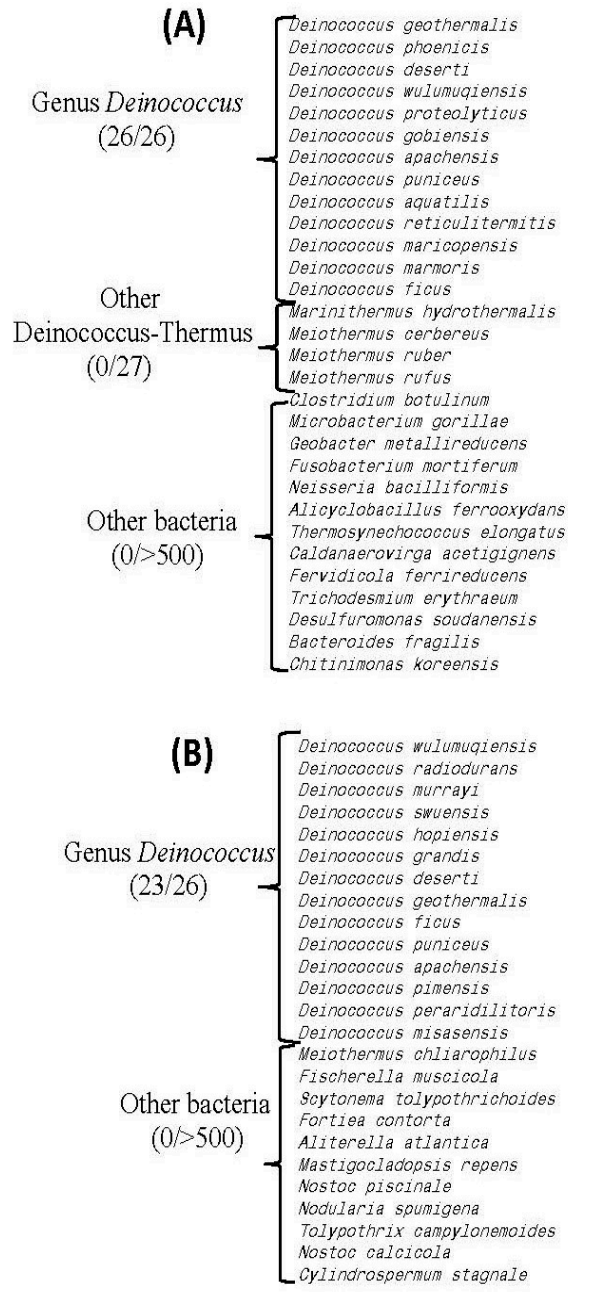

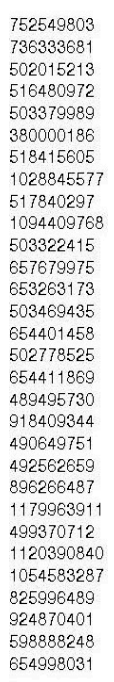

516481771
26401238
1181200112
746724932
1180560533
972314204
502015847
499850210
653261116
1028846531
518416739
653296726
505050133
736316365
916596753
515344547
1180032044
516249545
769920576
515887728
1011375201
1028121220
7515262650
1121336957
505022395
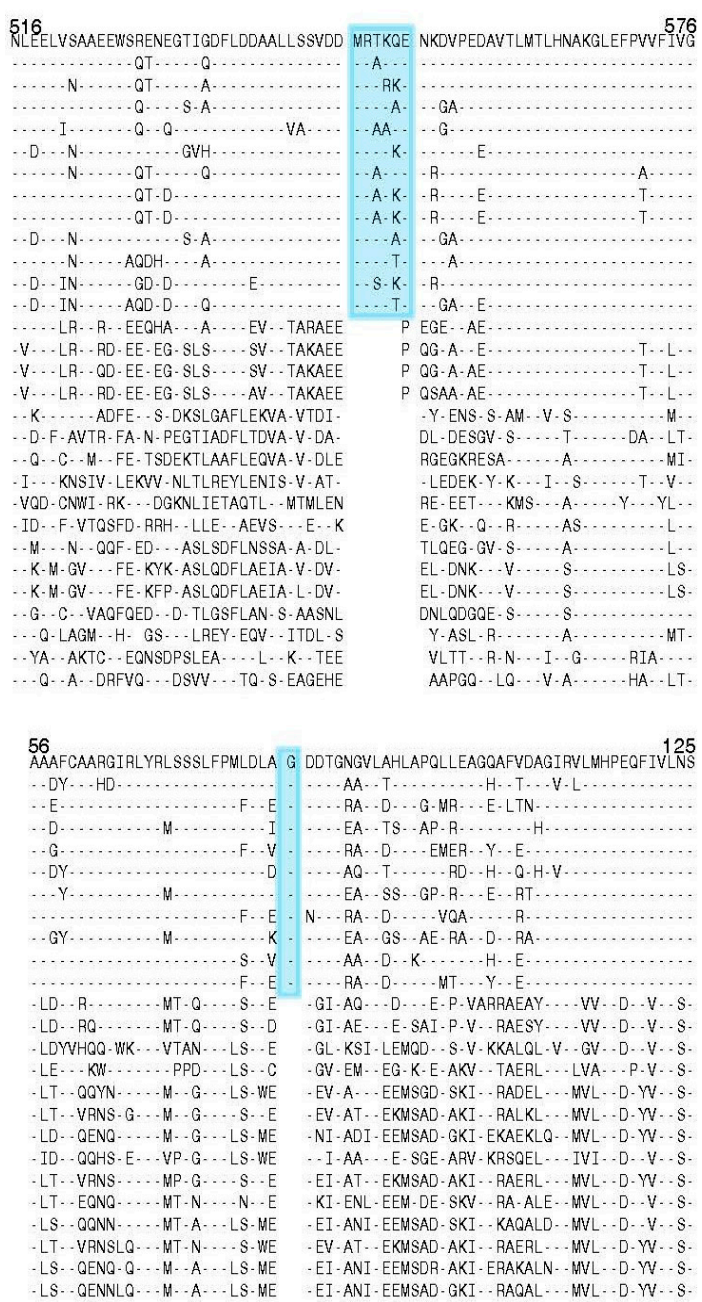

Figure 2. Partial sequence alignment showing conserved indels in (A) DNA helicase (UvrD) protein and (B) UV damage endonuclease (UvsE) protein which are specific for Deinococcus.

\subsection{Locations of the Conserved Indels (CSIs) in the Structures of the Proteins}

The locations of the identified CSIs in the structures of a number of DNA repair proteins viz. UvrA1, UvrC, UvrD and UvsE, were examined. Of these four proteins, three dimensional structure of $U v r D$ protein is available from $D$. radiodurans [78]. For the other three proteins, three-dimensional structural models for the $D$. radiodurans homologs were constructed by the homology modeling approach using suitable available template structures as described in the Methods section [63].

All of the generated models were of good stereo-chemical qualities as assessed by means of five independent structural validation servers (see Methods section). The locations (surface representations) of the identified CSIs in the structures of the modeled or solved structures of the proteins UvrA1, UvrC, UvrD and UvsE are shown in Figure 3. In addition, this figure also presents information regarding the secondary structures of the CSI-containing region (shown on top in purple color) as predicted by the PSIPRED server [64]. As seen from Figure 3, the CSIs in the UvrA1, UvrC and UvsE proteins are present in surface exposed loops of the modeled proteins. The 6 amino acid CSI in the UvrD protein is also located on the protein surface but it is present within an alpha helix, which appears to play a role in stabilizing the binding of the adjacent loop with the single-stranded DNA [78]. 
(A)
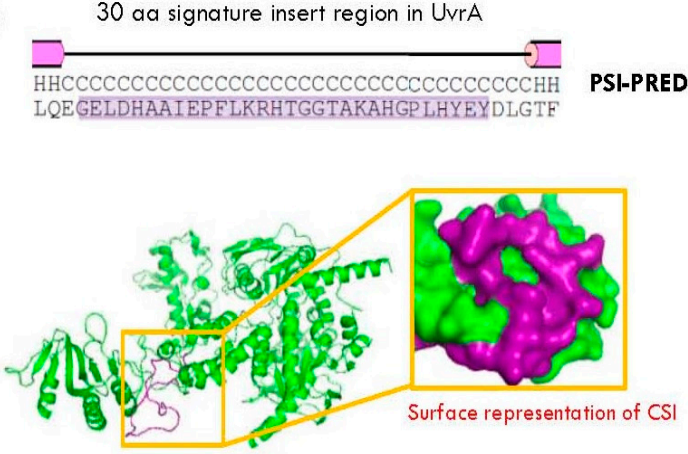

Cartoon structure of protein
(B)

B) 16 a signature insert region in UvrC

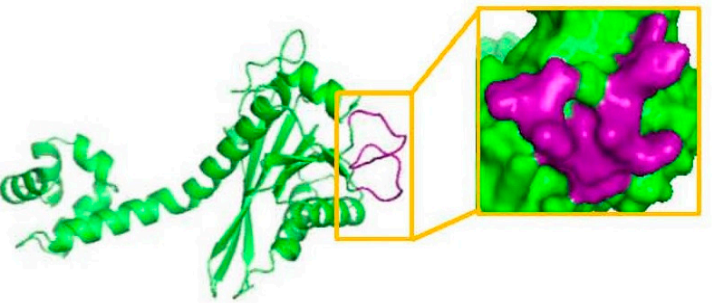

(C) 6 aa signature insert region in UvrD $-\sqrt{ }-$ DDMRTKAE PDB

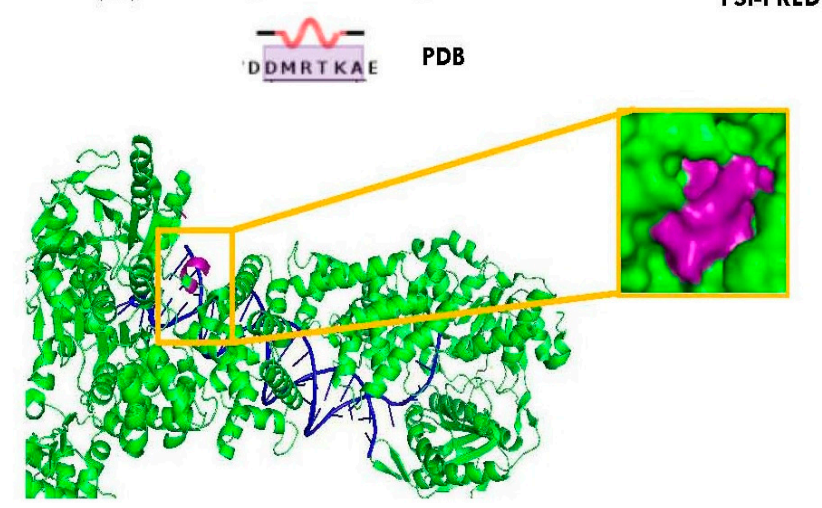

PSI-PRED

(D)

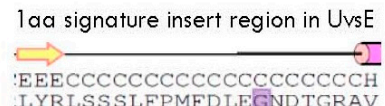

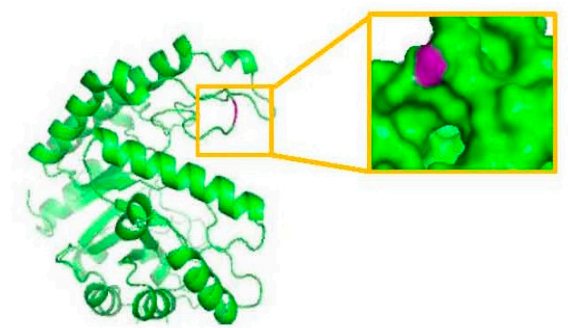

Figure 3. Secondary structure characteristics and structural locations of the identified CSIs in some DNA repair proteins. (A) Carton and surface representation of the location of the 30 amino acid CSI in the modeled structure of the UvrA1 protein from D. radiodurans; (B) Location of the 16 amino acid CSI in the modeled structure of UvrC protein; (C) Cartoon and surface representation of a 6 amino acid CSI in crystalized UvrD protein (PDB id: 4C2T); (D) Structural analysis of the 1 amino acid CSI in UvsE protein in the modeled structure of $D$. radiodurans.

\subsection{Novel Genomic Organization-Linkage of the Genes for UvrA1 and UvsE Proteins in Deinococcus Species}

The CSIs in most studied proteins are located in surface loops and commonly involved in facilitating novel protein-protein or protein-ligand interactions [37-40]. To determine, whether any of the CSI-harboring proteins from Deinococcus exhibit any novel interactions, the interaction profiles of different CSI-containing proteins was investigated using the STRING database [61]. This database predicts protein-protein interactions (PPIs) based on experimental data as well as co-occurrence of the proteins, gene fusion data, co-expression of the proteins and genetic neighborhood analysis $[61,62]$. Of the different DNA repair proteins containing the CSIs, the STRING server predicted novel protein-protein interactions for two proteins. In the first case, UvrA1 protein from Deinococcus was found to exhibit unique interactions with three other proteins based on its conserved genomic neighborhood. The three proteins whose genes were found to be in the immediate neighborhood of the uvrA1 gene from Deinococcus included a conserved Deinococcus-specific CSP, which is referred to here as dCSP-1 (for Deinococcus-specific conserved signature protein-1; accession number NP_295493) and two other proteins DsbA and DsbB, which are known to play central roles in disulfide bond formation in proteins [50-52]. In the STRING database, information regarding PPIs was present for only five Deinococcus species (D. radiodurans, Deinococcus geothermalis, Deinococcus deserti, Deinococcus proteolyticus and Deinococcus maricopensis) and of these four species, all except $D$. radiodurans showed a genetic 
linkage of the uvrA1 to the genes for the above three proteins (Figure 4). In case of D. radiodurans, only the gene for the dCSP-1 protein was indicated to be in the immediate neighborhood of the uvrA1 gene. In contrast to the Deinococcus species, no other bacterial species exhibited any genetic linkage of the uvrA gene to the genes for any of these proteins.

D. deserti

D. proteolyticus

D. geothermalis

D. maricopensis

D. gobiensis

D. actinosclerus

D. swuensis

D. soli

D. murray

D. phoenicis

D. frigens

D. marmoris

D. aerius

D. radiodurans

D. wulumuqiensis

D. deserti

D. proteolyticus

D. fiscus

Thermus thermophilus

Clostridium botulinum Escherichia coli
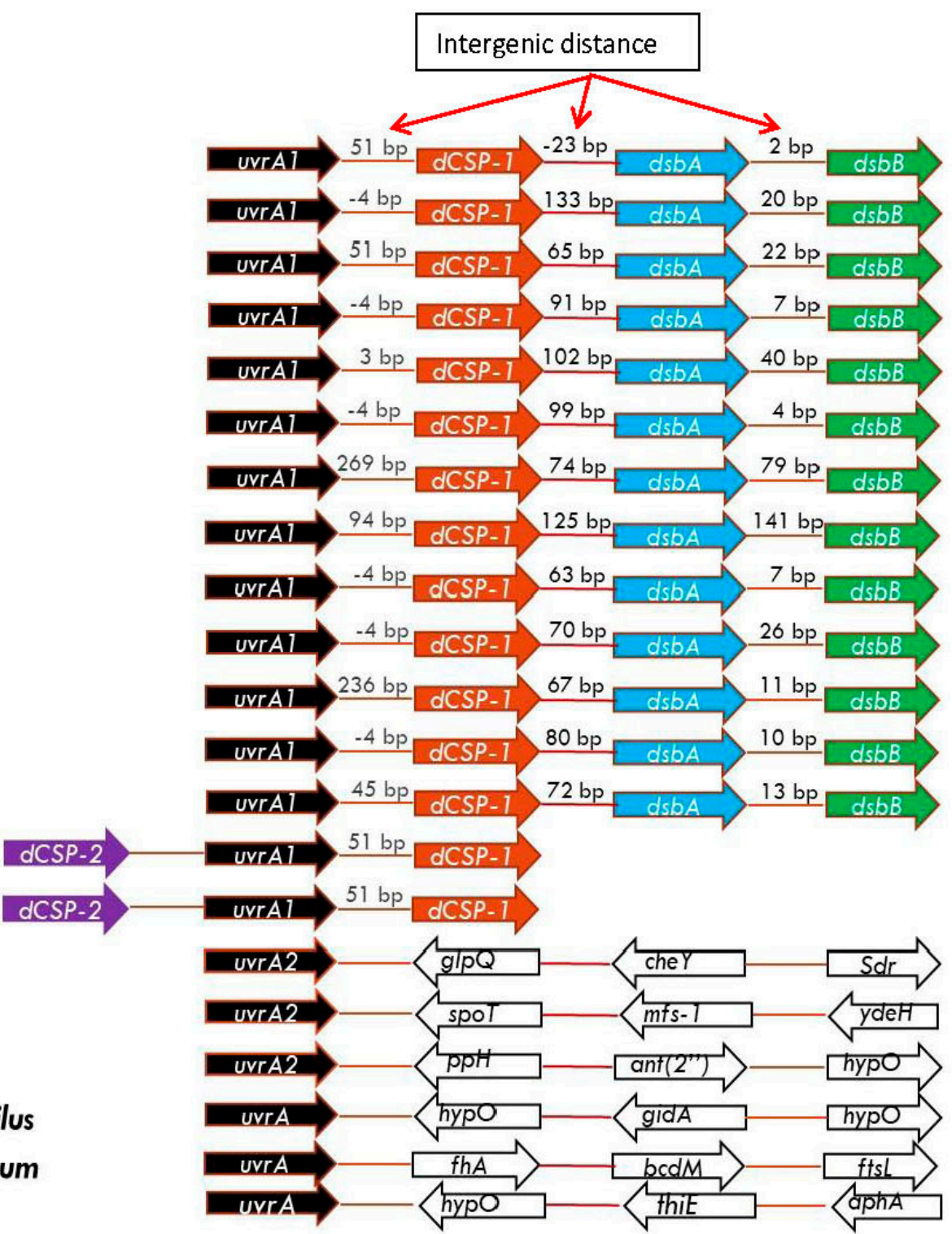

Figure 4. Genomic neighborhood of the gene for UvrA1 protein from Deinococcus species showing its specific linkage to the genes for dCSP-1, DsbA and DsbB proteins. The genes for these four proteins are oriented in the same direction and their intergenic distances in most cases are $<100$ base pairs indicating that they likely form an operon. The genes for UvrA2 from Deinococcus as well as the uvrA genes from other bacterial groups do not show specific genetic linkage to genes for any of these proteins. In $D$. radiodurans and $D$. wulumuqiensis, the gene for UvrA1 shows specific genetic linkage to the genes for dCSP-2 and dCSP-1 proteins, both of which are Deinococcus-specific.

The close genetic linkage of the uvrA1 gene in Deinococcus species to the genes for the above three proteins by STRING analysis prompted us to examine in detail the genomic neighborhood of the uvrA1 gene in all available Deinococcus genomes. For these studies, the genomic neighborhood of the $u v r A 1$ gene was manually examined in different Deinococcus genomes and a summary of the results of these analyses is presented in Figure 4. These studies revealed that of the 26 Deinococcus 
genomes currently available, 24 of them exhibited identical genomic organization where the genes for dCSP-1, DsbA and DsbB proteins were present in the immediate neighborhood of the uvrA1 gene and their relative gene orders as well as orientations were identical (Figure 4). In the remaining two genomes, corresponding to $D$. radiodurans and $D$. wulumuqiensis, only the gene for the dCSP- 1 was found immediately downstream of the $u v r A 1$ gene but the linkage to the genes for DsbA and DsbB proteins was not observed (Figure 4). However, in these two species, the gene for another novel CSP referred to here as dCSP-2 (Accession number WP_010888407.1), which is only found in D. radiodurans and $D$. wulumuqiensis, was located immediately upstream of the $u v r A 1$ gene. The indicated novel genomic arrangements were only observed for the uvrA1 gene from Deinococcus species and similar gene arrangement was not found in any other studied bacteria (Figure 4 and other results not shown). As noted earlier, Deinococcus species contain another homolog of the UvrA protein (UvrA2) $[79,80]$ and the gene for this homolog also exhibited no linkage to these genes (Figure 4). In all of these cases, the genes in the neighborhood of $u v r A$ were found to be different and showed no specific pattern (Figure 4).

In prokaryotic organisms, $\sim 60 \%$ of the genes are present in polycistronic operons [81,82]. An operon consists of a cluster of genes arranged in tandem on the same strand of a genome sharing common promoter and terminator. The specific linkage of the genes for UvrA1, dCSP-1, DsbA and DsbB proteins in most Deinococcus species and of the genes for dCSP-2, UvrA1 and dCSP-1 in $D$. radiodurans and $D$. wulumuqiensis, suggests that these two sets of genes likely form distinct operons. This inference is consistent with the observation that all of these genes are present on the same strand of DNA and they are transcribed in the same direction. We have also measured the genetic distances between these genes in different Deinococcus genomes and in most cases, the intergenic distances separating these genes are $<100$ base pairs (bp) (Figure 4). Analyses of genes from well-studied prokaryotic species indicate that when the genetic distance between two gene exhibiting similar phylogenetic profiles is $<200 \mathrm{bp}$, there is a strong likelihood that these genes are part of an operon [82]. We also used the DOOR 2.0 database to determine whether the genes for these four proteins are part of an operon [83]. The DOOR 2.0 database contains computationally predicted operons of prokaryotic genomes and its accuracy for correctly predicting the operonic organization for Bacillus subtilis and E. coli is $>90 \%$ [83]. Information for six Deinococcus species was available in the DOOR 2.0 database and based on its computational prediction, the genes for UvrA1, dCSP-1, DsbA and DsbB proteins were present in a single operon in 3 out of 6 species (viz. D. deserti, D. gobiensis and D. geothermalis). Of the remaining three species, in D. proteolyticus and D. maricopensis, the genes for UvrA1 and dCSP-1 proteins were indicated to be part of one operon, whereas the genes for DsbA and DsbB proteins were part of an adjacent operon. However, since the intergenic distance between these two neighboring sets of genes (or operons) is $<100 \mathrm{bp}$, it is highly likely that all four of these genes are part of a single operon. In $D$. radiodurans, an operonic arrangement was observed only for the genes for dCSP-2, UvrA1 and dCSP-1 proteins and the genes for DsbA and DsbB were not present in its neighborhood [82,83].

Besides the UvrA1 protein, our genetic neighborhood analysis also reveals that the gene for the UvsE protein in Deinococcus species also exhibits a novel and specific genetic linkage to the gene for a Zn-ribbon (Zn-R) protein (accession number AFD24462.1) (Figure 5). The DOOR.2 database also predicts that the genes for UvsE and Zn-R are part of an operon in Deinococcus species. 


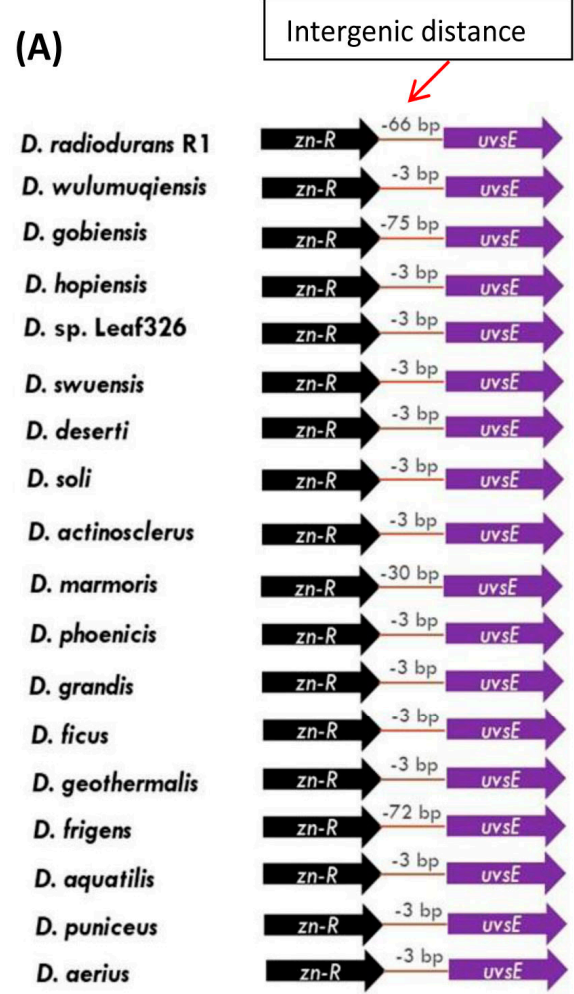

(B)
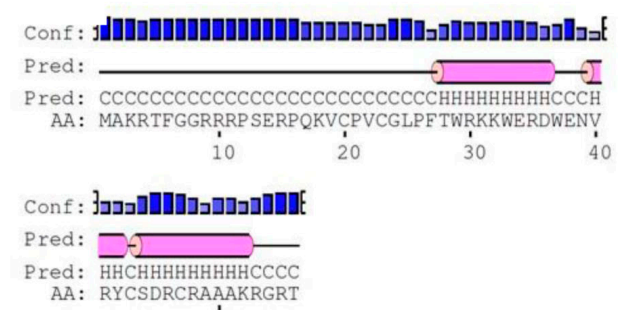

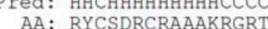

50

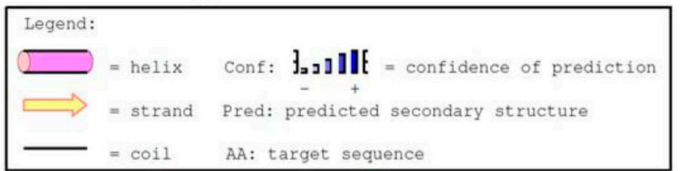

(C)

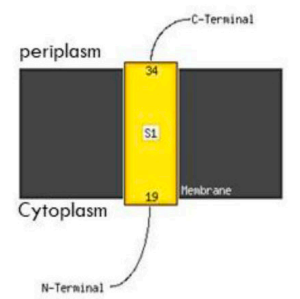

Figure 5. (A) Genomic neighborhood analysis of the gene for UvsE protein showing its specific genetic linkage in Deinococcus species to the gene for Zn-ribbon protein (Zn-R). The genes for these two proteins are oriented in the same direction and their coding regions overlap suggesting that they form an operon. (B and C) Predicted secondary structure and membrane topology of the Zn-ribbon protein (Accession ID: AFD24462.1).

\subsection{Structural and Biochemical Characteristics of the Proteins Linked to the UvrA1 Protein}

Our results indicate that the genes for UvrA1, dCSP-1, DsbA and DsbB proteins in Deinococcus species exhibit specific genetic linkage and they likely form an operon. As the genes within an operon generally carry out related functions $[82,84,85]$, it is of much interest to understand the functions of the three proteins that are genetically linked to the UvrA1 protein. Of these three proteins, dCSP-1 is a protein that is uniquely found in Deinococcus species. In our earlier work, this protein was identified as a CSP that was specifically found in all Deinococcus species for which genome sequence information was available [5,22]. The specificity of this protein for Deinococcus species was re-examined by BLASTp searches and the results obtained confirm that this protein is a distinctive characteristic of all Deinococcus species (Appendix A, Figure A1).

The protein dCSP-1 (NP_295493) is 247 amino acids long in D. radiodurans and it is annotated as a hypothetical protein of unknown function. To gain insights into the possible function of this protein, its sequence was analyzed using the PSIPRED server [64]. This server uses multiple methods for predicting secondary structure of proteins and it also indicates whether a given protein is a membrane protein and its membrane topology [64]. The secondary structure predicted for the dCSP-1 by the PSIPRED server is shown in Figure 6A. Most of the residues from dCSP- 1 are present in 6 alpha helices (shown in magenta color) and it contains only a small beta strand region shown in yellow. Based on its predominantly helical structure, the PSIPRED server predicts that dCSP-1 is a transmembrane protein containing five membrane-spanning regions and its overall membrane topology is as shown in Figure 6B. 
(A)

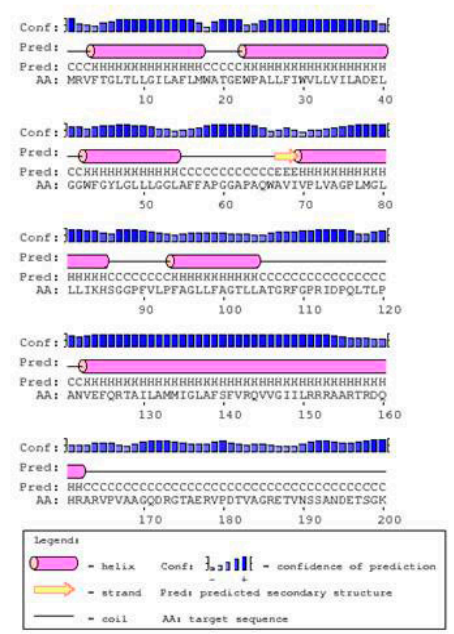

(B)

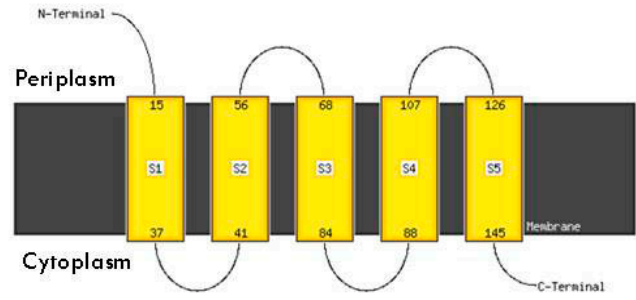

Figure 6. Secondary structure prediction (A) and membrane topology (B) of the dCSP-1 protein (Accession ID: NP_295493). Most residues in this protein are present in helix regions and it is predicted to be a cytoplasmic membrane protein with five transmembrane helices.

The other two proteins DsbA and DsbB, showing genetic linkage to the UvrA1 and dCSP-1 proteins function together in the formation of disulfide bonds in proteins [50,51]. Of these, DsbA is localized in the periplasmic space and it catalyzes intrachain disulfide bond formation in newly formed proteins as they emerge in the periplasm. The continued functioning of DsbA requires DsbB, which is a cytoplasmic membrane protein containing two CXXC motifs, which oxidizes DsbA to regenerate its active form $[50,51,86]$. We have examined whether the proteins DsbA or DsbB contain any novel sequence features that are specific for the Deinococcus species. These studies have identified a 5-7 amino acid insert in a highly conserved region of the DsbA protein that is specifically present in all Deinococcus-species (Figure 7). While all other Deinococcus species contain a 7 amino acid insertion in the DsbA, D. radiodurans and D. wulumuqiensis contain a shorter 5 amino acid insert in the same position (Figure 7).
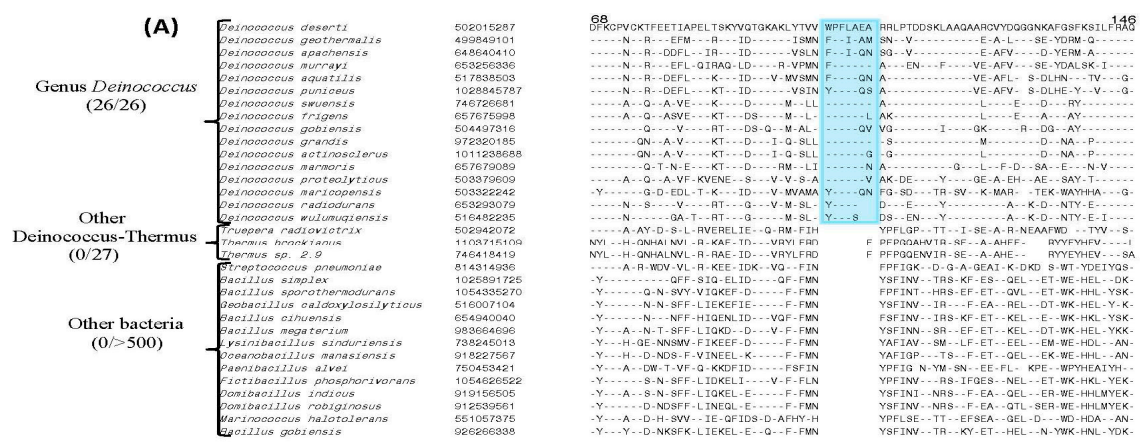

(B)

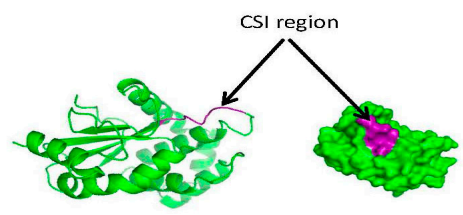

Figure 7. (A) Partial sequence alignment of the DsbA oxidoreductase protein showing a 5-7 amino acid insertion in a conserved region that is specific for Deinococcus species; (B) Location of the CSI in the modeled structure of DsbA protein from $D$. deserti constructed using the template structure of DsbA protein from Bacillus subtilis (PDB id: 3eu3). 
As noted above, the gene for the UvsE protein also exhibits a specific genetic linkage to the gene for a $\mathrm{Zn}$-ribbon (Zn-R) protein in Deinococcus species (Figure 5A). The genes for these two proteins show partial overlap in most Deinococcus species (Figure 5A). The Zn-ribbon protein linked to UvsE is 67 aa long and analysis of its sequence by the PSIPRED server indicates that this protein also contains a transmembrane helix (Figure $5 \mathrm{~B}$ ) and is predicted to be a cytoplasmic membrane protein (Figure 5C).

\subsection{Presence of CXXC Motifs in DNA Repair Proteins}

The observed genetic linkage of UvrA1 to the DsbA and DsbB proteins, which provide the main cellular machinery for oxidation-reduction of CXXC motifs in proteins, indicates that this aspect should be of importance for Deinococcus species. Hence, we have examined the sequences of various DNA repair proteins for the presence of CXXC motifs. The results of our analysis indicate that CXXC motifs are present in a large number of DNA repair proteins including UvrA1, DNA ligase, DNA polymerase II subunit gamma/tau, MutY, MutM, Nth, Rad 25, RecO, RecR, RecQ, SbcC and RadA (Appendix A Table A1 and Figure S17(A-L)). While all other DNA repair proteins listed in Table A1 contain either one or two CXXC motifs, the UvrA1 protein is found to contain five CXXC motifs, indicating that these motifs should play important role in the functioning of this protein. All of the CXXC motifs in UvrA1 are located on protein surface and they are parts of three zinc finger elements $[47,55]$, commonly utilized by proteins for binding to specific regions in DNA or for mediating protein-protein interactions $[55,56,66,79,87,88]$. Partial sequence alignment of the UvrA protein showing two of the CXXC motifs, which are present near the C-terminal end, as well as the locations of these motifs in the structure of UvrA are shown in Figure 8. Earlier work has shown that substitution of one of the cysteine (marked in red) from these CXXC motif causes functional inactivation of the UvrA1 protein [54].

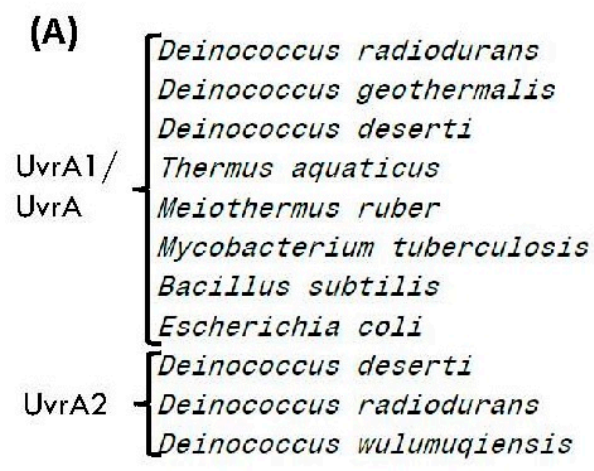

(B)

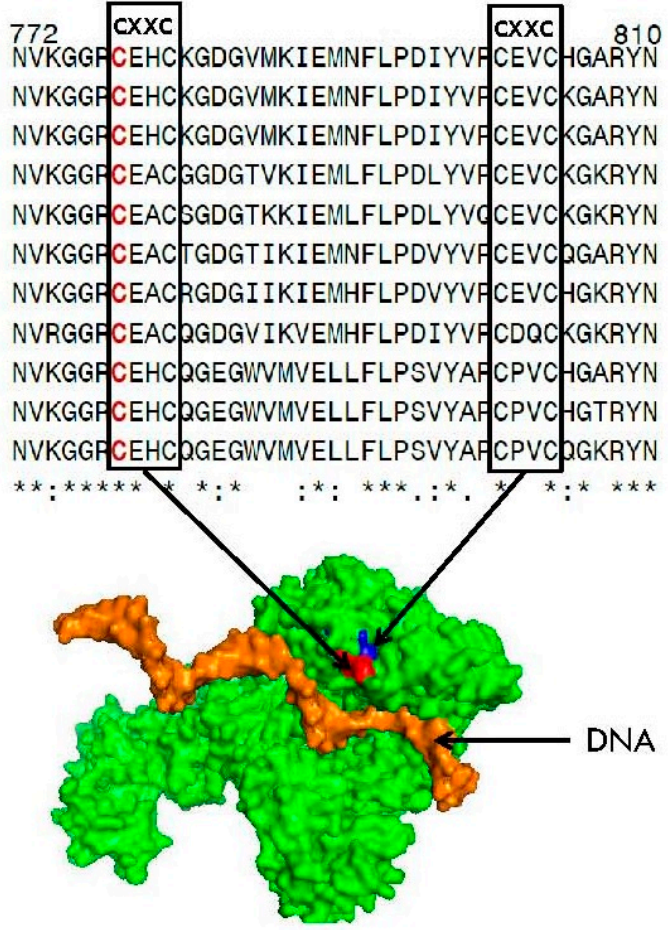

Figure 8. (A) Partial sequence alignment of the C-terminal region from UvrA protein showing the presence of a Zinc-finger element containing CXXC motifs. The CXXC motifs shown here are conserved in all UvrA homologs. Mutational studies on the cysteine residue marked in red indicates that it plays an important role in the functioning of the UvrA protein $[54,56]$; (B) Location of two the CXXC motifs, which are part of a Zinc finger element, in the structure of UvrA protein. 


\section{Discussion}

Deinococcus species are highly resistant to UV and ionizing radiations and prolonged desiccation, due to their ability to protect their proteome from the harmful effects of ROS [12,14,19,20,28,89]. However, the biochemical mechanisms enabling these bacteria to protect their critical proteome from oxidatively-generated damage remain unidentified [12]. In this context, the results of our comparative analyses of DNA repair proteins, which have identified multiple highly-specific molecular signatures in the forms of CSIs that are specific for Deinococcus homologs, are of much interest. Earlier work on CSIs provides evidence that the genetic changes of this kind play important functional roles in the organisms for which they are specific $[38,39,90]$. Further, most of the studied CSIs in proteins, including in the DNA repair proteins examined in the present work, are present in surface loops of proteins, which are generally involved in mediating novel protein-protein or protein-DNA (ligand) interactions $[5,37,39,40]$. While the possible cellular functions of most of the CSIs identified in this study remains to be delineated, a number of novel observations reported here provide important insights into the possible cellular function of a large CSI found in the UvrA1 protein. The UvrA1 protein is a central component of the NER pathway comprising of the UvrABC proteins $[12,47,48,87]$. This protein is unique in its ability to recognize a broad range of DNA damages including cyclobutane pyrimidine dimers and 6,4-photoproducts formed by UV light and multiple other types of damaged nucleotides/bases resulting from exposure to ionizing radiation $[12,47,48,87]$. Following, initial DNA damage identification by UvrA1, other proteins in the pathway viz. UvrB and UvrC, excise the damaged region and the gap created is filled by DNA polymerase I and subsequently ligated by DNA ligase $[12,47,48,87]$. Although Deinococcus species contain two different UvrA homologs, only the UvrA1 protein but not UvrA2, plays an important role in DNA repair process [80]. The gene for UvrA1 protein is also induced upon radiation and desiccation [12]. The present work has identified two novel characteristics of the UvrA1 protein that are uniquely observed for Deinococcus species. First, the UvrA1 protein from Deinococcus contains a 30 amino acid insertion in a conserved region that is absent in all other UvrA homologs (including UvrA2). Second, the gene for UvrA1 in all Deinococcus species is linked to the gene for a novel protein (dCSP-1) that is only found in different Deinococcus species. Additionally, in most Deinococcus species, except $D$. radiodurans and D. wulumuqiensis, the genes for $u v r A 1$ and $d C S P-1$ are also specifically linked to the genes for DsbA and DsbB proteins and all four of these genes are predicted to form an operon. This novel arrangement/linkage of genes i.e., uvrA1-dCSP-1-dsbA-dsbB is only seen in Deinococcus species but in no other bacteria.

Of the three proteins genetically linked to UvrA1, dCSP-1 is a transmembrane protein, similar to the DsbB protein. The other two proteins, DsbA and DsbB, are both involved in the formation of intrachain disulfide bonds in proteins by catalyzing oxidation-reduction of cysteine residues in protein sequences. Of these, DsbA is localized in periplasm, whereas DsbB is an integral cytoplasmic membrane protein. As most of the proteins showing genetic-linkage to the Deinococcus UvrA1 are either cytoplasmic membrane or periplasmic proteins and two of them whose functions are known are involved in the oxidation-reduction of cysteine residues in proteins, it focuses attention on the significance of cysteine oxidation-reduction and membrane association in the functioning of UvrA1 protein. There is now considerable evidence that proteins are the major initial targets of free radicals or ROS in comparison to either DNA or lipids [19,29,30,89]. In proteins, cysteine residues, when present, generally serve important catalytic, regulatory, structure-stabilizing, or metal and cofactor binding functions and they are highly susceptible to modification by reactive oxygen species [53,91]. Many cytosolic proteins involved in catalyzing oxidation-reduction reactions contain CXXC motifs and the Cys residues in them exist as highly-reactive thiolate $\left(\mathrm{S}^{-}\right)$ions, whose oxidation can result in the functional inactivation of proteins $[30,53,91,92]$. In this context, it is of much interest that cysteine residues and CXXC motifs are present in a large number of DNA repair proteins (Table A1 and Figure S17). Of particular interest in this context is the fact that of all the DNA repair proteins, maximal numbers of CXXC motifs (5 in comparison to $0-2$ found in other proteins) are present in the UvrA1 protein and they are parts of zinc finger elements, which play important roles in the binding 
of UvrA to DNA and in DNA damage recognition [54-56,88]. The above characteristics of the UvrA protein make it a prime target to be affected by oxidative stress and ROS. The importance of cysteine residues in the functioning of UvrA protein is also supported by a number of other observations: (i) Substitution of a cysteine in one of the C-terminal CXXC motifs causes inactivation of the UvrA protein [54]; (ii) Treatment of D. radiodurans with iodoacetamide (IAA), which alkylates -SH groups in cysteines, abolishes or greatly reduces its radiation resistance [93]; (iii) Treatment with IAA also causes repression (or inactivation) of a protein that excises DNA from a DNA-membrane complex [94,95]; (iv) Irradiation of $D$. radiodurans in presence of cysteine, which should protect Cys residues in proteins from oxidation, decreases their radiation sensitivity [96]; (v) Treatment of Deinococcus with sublethal concentration of cadmium leads to upregulations of a large number of genes involved in cysteine biosynthesis and disulfide stress indicating the importance of Cys-related systems in resistance to oxidative stress [97]. A number of observations also indicate that the cellular function of UvrA involves interaction with membrane. Based on earlier studies DNA in unirradiated Deinococcus is bound to membrane and it dissociates from membrane upon radiation treatment; importantly the re-association of DNA with membrane is inhibited by IAA $[94,98,99]$. Further, it has been reported that following UV irradiation, many DNA repair proteins relocate to the inner membrane and UvrA protein serves as a site of attachment for these proteins to the membrane [100].

Based on the above observations, to account for the different novel properties of the UvrA1 gene/protein from Deinococcus species reported here and how they may serve to protect this protein from oxidatively generated damage, we are proposing a model shown in Figure 9.

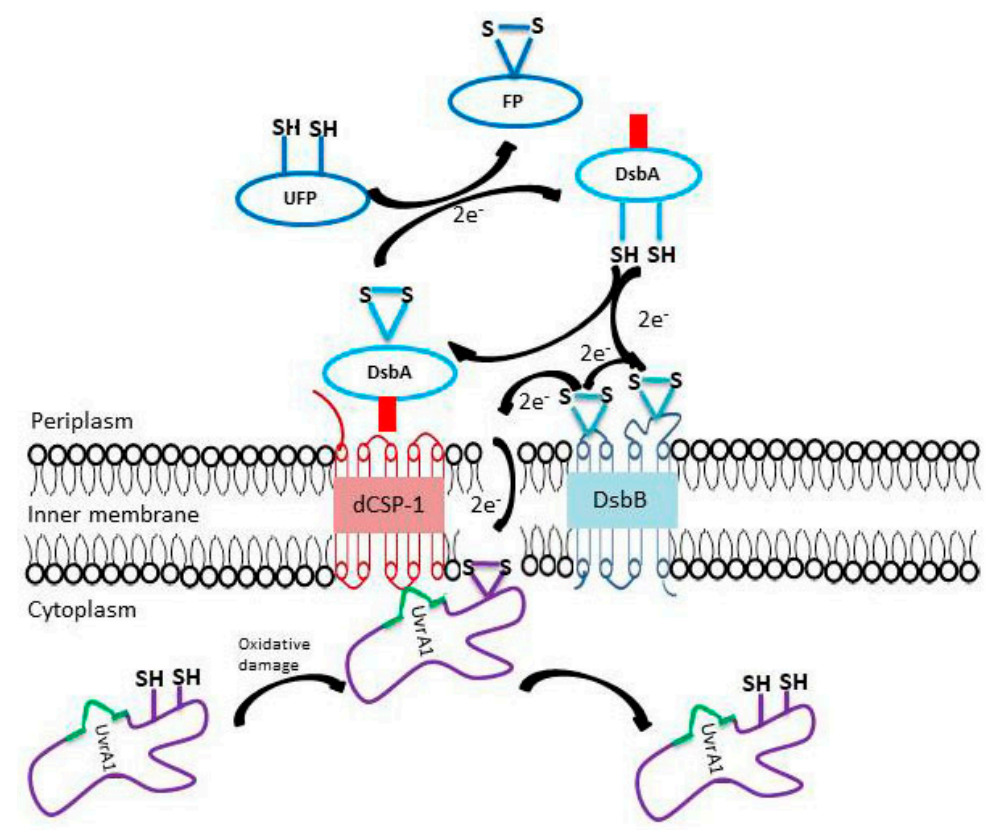

Figure 9. Proposed model to account for the novel genomic-proteomic characteristics of the UvrA1 gene/protein from Deinococcus species and their possible roles in protection of this protein from oxidatively generated damage. The model shown here proposes that the 5-7 amino acid insert present specifically in the Deinococcus DsbA protein (shown in red) plays a role in its interaction with the membrane embedded Deinococcus-specific protein dCSP-1. The model also suggests that the 30 amino acids insert found uniquely in Deinococcus UvrA1 homologs allows specific interaction with the dCSP-1 protein. These interactions position the UvrA1 protein in the proximity of cytoplasmic membrane such that the CXXC motifs in UvrA1 can receive electrons from DsbB protein to reduce oxidized cysteines and regenerate the functional non-oxidized form of the UvrA1 protein. The arrows indicate the direction of electron flow from DsbA to DsbB and to the membrane-associated UvrA1 protein. FP and UFP refer to folded and unfolded proteins. 
In this model, the proteins DsbA and DsbB, both of which contain CXXC motifs, are located in periplasm and cytoplasmic membrane, respectively, performing their well-studied functions in the oxidation-reduction of disulfide bonds in proteins [50,51,101,102]. A CXXC motif present at the active site of DsbA serves as the primary donor of disulfide bond to other unfolded proteins (UFP) in the periplasmic space. The reduced form of DsbA is reoxidized by transfer of electrons to the CXXC motifs in the DsbB protein and reducing it $[50,51,101,102]$. The DsbA protein in Deinococcus contains a 5-7 amino acid insert (shown in red) that is uniquely found in these bacteria. The model proposes that one possible function of this insert could be to enable specific interaction between the DsbA protein of Deinococcus and the membrane embedded dCSP-1 protein, which is also uniquely found in these bacteria. Another novel characteristic of Deinococcus identified in this work is the 30 amino acid insertion in the UvrA1 protein (shown in green in Figure 9). We are suggesting that one possible function of this insert in UvrA1 is to enable specific interaction with the dCSP-1 protein, thereby linking the UvrA1 to the dCSP-1, DsbA and DsbB proteins. The observed close genetic linkage of the uvrA1 and $d C S P-1$ also suggests the possibility that these two proteins are co-expressed under different conditions. It is suggested that the proposed interactions between the insert in the UvrA1 protein and dCSP-1 and the insert in DsbA protein and dCSP-1, the characteristics which are distinctive of Deinococcus species, serve to position the UvrA1 protein in Deinococcus in the proximity of membrane-bound DsbB protein (Figure 9). The reduced form of DsbB generally transfers electrons to the terminal oxidases via the quinone cofactor [50,51,101-103]. However, in Deinococcus species, we are proposing that due to the specific association of UvrA1 with the membrane embedded dCSP-1, electrons transfer can occur from DsbB (either directly or through quinone intermediate) to the oxidized CXXC motifs in the UvrA1 protein, thereby removing oxidative damage from this critical protein and restoring it into its non-oxidized functional state (Figure 9).

It should be noted that while DsbA homologs from most Deinococcus species contain a 7 amino acid insertion (Figure 7), the insert in D. radiodurans and D. wulumuqiensis is 5 amino acids long. In these two Deinococcus species, the genes for UvrA1 and dCSP-1 are also not genetically linked to the genes for DsbA and DsbB proteins but instead they exhibit a close genetic linkage to the gene for another novel protein dCSP-2, which is only found in these two Deinococcus species. The protein dCSP-2 is also predicted to be a membrane-associated protein and it is possible that this protein functioning in conjunction with the shorter CSI found in the DsbA homologs of these species, enables/augment specific interaction between the DsbA and dCSP-1 proteins in these two Deinococcus species.

In addition to the unique genetic linkage of the Deinococcus UvrA1 to the membrane associated dCSP-1, DsbA and DsbB proteins, a number of other important DNA repair proteins in Deinococcus species contain novel sequence features and some of them exhibit unique genetic linkages to membrane-associated proteins. We have shown in this work that the UvsE protein, central to the UvsE-dependent pathway of excision DNA repair [12,49], also contains a 1 amino acid CSI that is distinctive of Deinococcus homologs and its gene exhibits a novel operonic arrangement in Deinococcus with the gene for a Zn-ribbon (Zn-R) protein, which is predicted to be a transmembrane protein (Figure 5). Further, it has been reported that the gene for RecA in D. radiodurans forms a polycistronic operon with the genes for CinA and LigT proteins [104]. Our analysis indicates that a specific genetic linkage of the genes for RecA, CinA and LigT is a shared characteristic of all Deinococcus-Themus species (see Figure S16). Further, it has been reported that the CinA protein binds RecA and locates it to the cell membrane [105]. Thus, it is possible that the membrane association of UvsE and RecA proteins, seen specifically in Deinococcus species may also serve to protect these proteins from oxidatively generated damage.

In summation, the present work has identified many novel sequence features in the DNA repair genome/proteome of Deinococcus species which are predicted to contribute towards the increased resistance of these organisms to radiation/desiccation and other oxidative stress inducing agents. While the model proposed in Figure 9 is consistent with a large number of observations, it is primarily based on novel sequence and structural characteristics of the UvrA1 protein from Deinococcus and 
other proteins whose genes are genetically linked to the UvrA1 protein in these bacteria. It would be important to confirm various aspects of the suggested model by means of experimental approaches. However, it should be noted that one observation which conflicts with the present model concerns the report that the uvrA gene from E. coli (which is similar to the uvrA2 gene found in Deinococcus) can complement the mitomycin C-sensitive phenotype of some D. radiodurans mutants [106]. This observation is surprising in view of the various novel sequence features of the UvrA1 gene/protein from Deinococcus species identified in this work, which distinguish it from all other homologs. Earlier work on CSIs and CSPs strongly indicates that these characteristics are functionally important for the group of organisms for which they are specific and deletion or mutational changes in them generally leads to functional inactivation $[38,39,90,107]$. Based on this, it is expected that the novel sequence features of the UvrA1 protein identified here should also serve important functions in Deinococcus species and that other UvrA homologs lacking these novel features, including the UvrA2 homolog from Deinococcus, should not be able to serve similar function. Thus, the ability of the E. coli uvrA gene to replace/complement the function of the uvrA1 gene of Deinococcus is contrary to these expectations and it needs to be investigated more thoroughly. The possible cellular functions of CSIs in other DNA repair proteins, which are specific for Deinococcus species also remains to be determined and further studies on them could provide other useful insights into novel functional aspects of other DNA proteins in Deinococcus.

Supplementary Materials: The following are available online at www.mdpi.com/2073-4425/9/3/149/s1. Figure S1: Partial sequence alignment of MutY protein showing a 4 aa CSI specific for Deinococcus; Figure S2: Partial sequence alignment of MutM protein showing a Deinococcus-specific CSI; Figure S3: Partial sequence alignment of Endonuclease III (Nth) protein showing a showing a Deinococcus-specific CSI; Figure S4: Partial sequence alignment of RecA protein showing a showing CSI specific for Deinococcus-Thermus; Figure S5: Partial sequence alignment of RecR protein showing a showing a showing CSI specific for Deinococcus-Thermus; Figure S6: Partial sequence alignment of DNA helicase RecQ protein showing a Deinococcus-specific CSI; Figure S7: Partial sequence alignments of RecD protein showing two 2 CSIs that are specific for Deinococcus; Figure S8: Partial sequence alignment of RuvC protein showing a Deinococcus-specific CSI; Figure S9: Partial sequence alignment of RecG protein showing a CSI that is specific for Deinococcus species; Figure S10: Partial sequence alignment of DNA polymerase I (PolA) showing a CSI that is specific for Deinococcus species; Figure S11: Partial sequence alignment of DNA polymerase III alpha (DnaE) showing a CSI that is specific for Deinococcus species; Figure S12: Partial sequence alignment of conserved region of DnaE protein showing another CSI that is specific for Deinococcus species; Figure S13: Partial sequence alignment of LigA protein showing a CSI that is specific for Deinococcus species; Figure S14: Partial sequence alignment of DNA gyrase A (GyrA) protein showing a 1 amino acid CSI that is uniquely shared by all Deinococcus homologs; Figure S15: Partial sequence alignment of GyrB protein showing a CSI that is specific for Deinococcus species; Figure S16: Genomic neighborhood of the recA gene from representative Deinococcus-Thermus spp.; Figure S17: Sequence alignment showing the presence of CXXC motifs (highlighted) in different DNA Repair proteins.

Acknowledgments: This work was supported by Research Grant number 249924 from the Natural Science and Engineering Research Council of Canada, awarded to Radhey S. Gupta.

Author Contributions: F.M.N.H.: Identification of CSIs, Genomic neighborhood analysis, homology modeling studies and enumeration of CXXX motifs in proteins, preliminary model to explain the results; R.S.G., Design, planning and supervision of the entire work, Data analysis and its possible significance, Interpretation of the results and manuscript writing, obtained funding for the project.

Conflicts of Interest: The authors declare no conflict of interest. 


\section{Appendix A}

Table A1. Presence of Cysteine Residues and CXXC Motifs in DNA Repair Proteins.

\begin{tabular}{|c|c|c|c|c|}
\hline Protein Name & Protein ID & \# Of Cys Residues & CXXC Motifs & Figure Number \\
\hline UvrA1 & DR1771 & 11 & 5 & Figure S17A \\
\hline AlkA & DR2074 & 3 & - & - \\
\hline Endonuclease V (Nfi) & DR2162 & 1 & - & - \\
\hline MutM & DR0493 & 5 & 2 & Figure S17B \\
\hline 8-Oxoguanine DNA glycosylase (MutY) & DR2285 & 6 & 1 & Figure S17C \\
\hline Endonuclease III (Nth) & DR0928 & 6 & 1 & Figure S17D \\
\hline Exonuclease III (Xth) & DR0354 & 2 & - & \\
\hline UvrB & DR2275 & 6 & - & - \\
\hline UvrC & DR1354 & 3 & - & - \\
\hline UvsE & DR1819 & 4 & - & - \\
\hline $\operatorname{Rad} 25$ & DRA0131 & 10 & 2 & Figure S17E \\
\hline $\operatorname{RecA}$ & DR2340 & 1 & - & - \\
\hline $\mathrm{RecO}$ & DR0819 & 4 & 2 & Figure S17F \\
\hline RecR & DR0198 & 5 & 2 & Figure S17G \\
\hline RecJ & DR1126 & 2 & - & - \\
\hline $\operatorname{RecN}$ & DR1477 & 1 & - & - \\
\hline RecQ & DR1289 & 9 & 1 & Figure S17H \\
\hline $\operatorname{Rec} \tilde{D}$ & DR1902 & 1 & - & - \\
\hline $\mathrm{SbcC}$ & DR1922 & 4 & 1 & Figure S17I \\
\hline SbcD & DR1921 & 1 & - & - \\
\hline RuvA & DR1274 & 1 & - & - \\
\hline RuvC & DR0440 & 2 & - & - \\
\hline RecG & DR1916 & 4 & - & - \\
\hline RadA & DR1105 & 5 & 2 & Figure S17J \\
\hline Rad54 DNA helicase & DR1259 & 3 & - & - \\
\hline DdrA & DR0423 & 2 & - & - \\
\hline MutL & DR1696 & 4 & - & - \\
\hline MutS & DR1039 & 4 & - & - \\
\hline PolA & DR1707 & 5 & - & - \\
\hline DNA polymerase III, $\alpha$ subunit (DnaE) & DR0507 & 14 & - & - \\
\hline DNA polymerase III $\varepsilon$ subunit (DnaQ) & DR0856 & 1 & - & - \\
\hline DNA polymerase III subunit beta & DR0001 & 1 & - & - \\
\hline DNA ligase (LigA) & DR2069 & 4 & 1 & Figure S17K \\
\hline DNA polymerase III subunit gamma/tau & DR2410 & 7 & 1 & Figure S17L \\
\hline UvrD & DR1775 & 1 & - & - \\
\hline Gyrase A(GyrA) & DR1913 & 1 & - & - \\
\hline Gyrase B(GyrB) & DR0906 & 2 & - & - \\
\hline
\end{tabular}




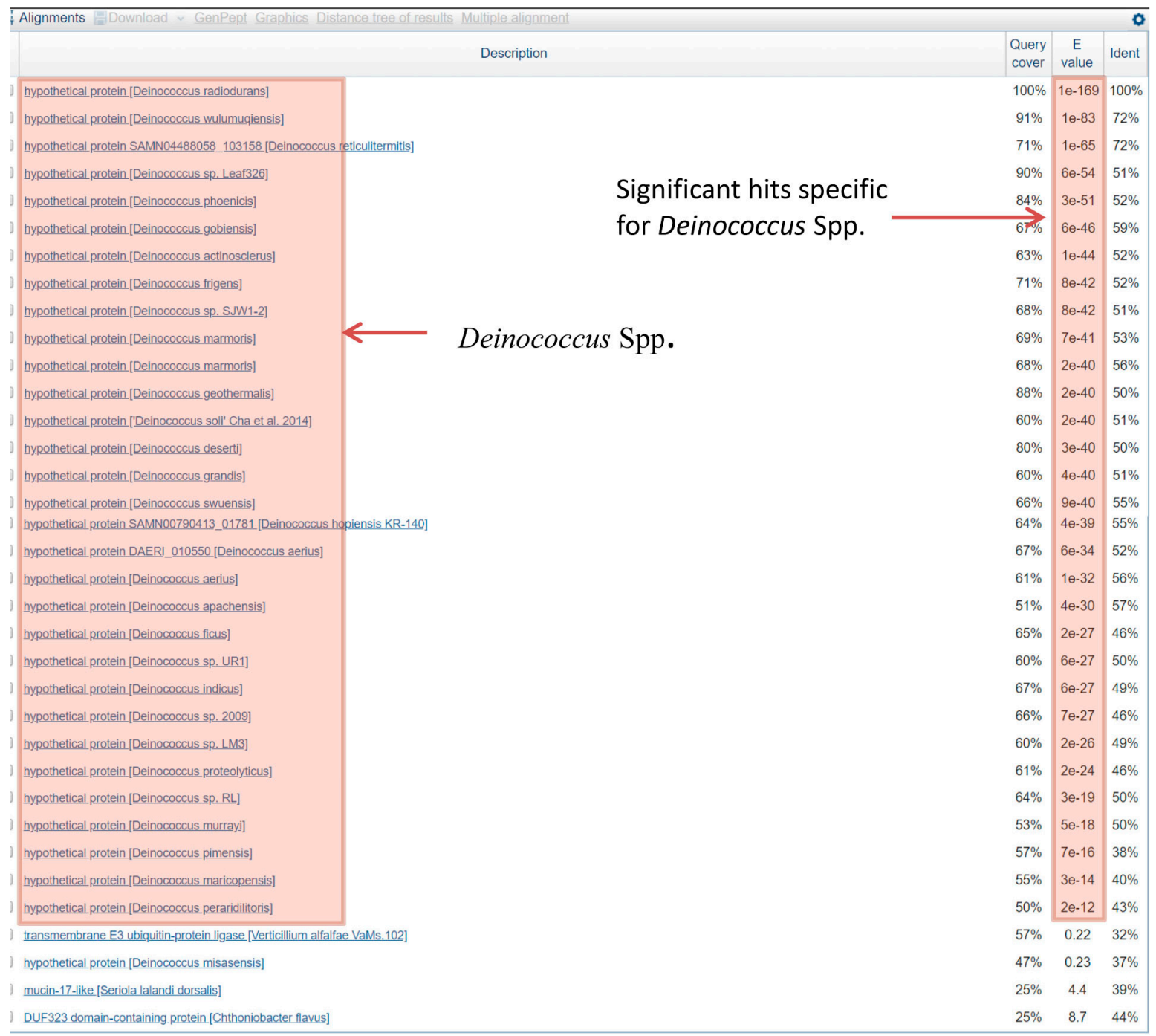

Figure A1. Blast Search Results Showing the Deinococcus specificity of the Protein dCSP-1.

All BLASTp hits showing significant similarity to the dCSP-1 protein (accession number NP_295493) are for Deinococcus species.

\section{References}

1. Battista, J.R.; Rainey, F.A.; Family, I. Deinococcaceae Brooks and Murray 1981, 356, VP emend. Rainey, Nobre, Schumann, Stackebrandt and da Costa 1997, 513. In Bergey's Manual of Systematic Bacteriology Volume 1, The Archaea and the Deeply Branching and Phototrophic Bacteria; Boone, D.R., Castenholz, R.W., Eds.; Springer: New York, NY, USA, 2001; pp. 395-403.

2. Battista, J.R.; Rainey, F.A.; Genus, I. Deinococcus Brooks and Murray 1981, 354, ${ }^{\mathrm{VP}}$ emend. Rainey, Nobre, Schumann, Stackebrandt and da Costa 1997, 513. In Bergey's Manual of Systematic Bacteriology vol.1, The Archaea and the Deeply Branching and Phototrophic Bacteria; Boone, D.R., Castenholz, R.W., Eds.; Springer: New York, NY, USA, 2001; pp. 396-403.

3. Rosenberg, E. The family Deinococcaceae. In The Prokaryotes-Other Major Lineages of Bacteria and the Archaea; Rosenberg, E., DeLong, E., Lory, S., Stackebrandt, E., Thompson, F., Eds.; Springer: New York, NY, USA, 2014; pp. 613-615.

4. Albuquerque, L.; Costa, M.S. The family Thermaceae. In The Prokaryotes-Other Major Lineages of Bacteria and the Archaea; Rosenberg, E., DeLong, E., Lory, S., Stackebrandt, E., Thompson, F., Eds.; Springer: New York, NY, USA, 2014; pp. 955-987. 
5. Ho, J.; Adeolu, M.; Khadka, B.; Gupta, R.S. Identification of distinctive molecular traits that are characteristic of the phylum "Deinococcus-Thermus" and distinguish its main constituent groups. Syst. Appl. Microbiol. 2016, 39, 453-463. [CrossRef] [PubMed]

6. Weisburg, W.G.; Giovannoni, S.J.; Woese, C.R. The Deinococcus-Thermus phylum and the effect of rRNA composition on phylogenetic tree construction. Syst. Appl. Microbiol. 1989, 11, 128-134. [CrossRef]

7. Cox, M.M.; Battista, J.R. Deinococcus radiodurans-The consummate survivor. Nat. Rev. Microbiol. 2005, 3, 882-892. [CrossRef] [PubMed]

8. Battista, J.R. Against all odds: The survival strategies of Deinococcus radiodurans. Annu. Rev. Microbiol. 1997, 51, 203-224. [CrossRef] [PubMed]

9. Krisko, A.; Radman, M. Biology of extreme radiation resistance: The way of Deinococcus radiodurans. Cold Spring Harb. Perspect. Biol. 2013, 5. [CrossRef] [PubMed]

10. Mattimore, V.; Battista, J.R. Radioresistance of Deinococcus radiodurans: Functions necessary to survive ionizing radiation are also necessary to survive prolonged desiccation. J. Bacteriol. 1996, 178, 633-637. [CrossRef] [PubMed]

11. Timmins, J.; Moe, E. A Decade of Biochemical and Structural Studies of the DNA Repair Machinery of Deinococcus radiodurans: Major Findings, Functional and Mechanistic Insight and Challenges. Comput. Struct. Biotechnol. J. 2016, 14, 168-176. [CrossRef] [PubMed]

12. Slade, D.; Radman, M. Oxidative stress resistance in Deinococcus radiodurans. Microbiol. Mol. Biol. Rev. 2011, 75, 133-191. [CrossRef] [PubMed]

13. Cox, M.M.; Keck, J.L.; Battista, J.R. Rising from the Ashes: DNA Repair in Deinococcus radiodurans. PLoS Genet. 2010, 6, e1000815. [CrossRef] [PubMed]

14. Daly, M.J. A new perspective on radiation resistance based on Deinococcus radiodurans. Nat. Rev. Microbiol. 2009, 7, 237-245. [CrossRef] [PubMed]

15. Blasius, M.; Sommer, S.; Hubscher, U. Deinococcus radiodurans: What belongs to the survival kit? Crit. Rev. Biochem. Mol. Biol. 2008, 43, 221-238. [CrossRef] [PubMed]

16. Makarova, K.S.; Aravind, L.; Wolf, Y.I.; Tatusov, R.L.; Minton, K.W.; Koonin, E.V.; Daly, M.J. Genome of the extremely radiation-resistant bacterium Deinococcus radiodurans viewed from the perspective of comparative genomics. Microbiol. Mol. Biol. Rev. 2001, 65, 44-79. [CrossRef] [PubMed]

17. Battista, J.R.; Earl, A.M.; Park, M.J. Why is Deinococcus radiodurans so resistant to ionizing radiation? Trends Microbiol. 1999, 7, 362-365. [CrossRef]

18. Minton, K.W. DNA repair in the extremely radioresistant bacterium Deinococcus radiodurans. Mol. Microbiol. 1994, 13, 9-15. [CrossRef] [PubMed]

19. Krisko, A.; Radman, M. Protein damage and death by radiation in Escherichia coli and Deinococcus radiodurans. Proc. Natl. Acad. Sci. USA 2010, 107, 14373-14377. [CrossRef] [PubMed]

20. Daly, M.J.; Gaidamakova, E.K.; Matrosova, V.Y.; Vasilenko, A.; Zhai, M.; Leapman, R.D.; Lai, B.; Ravel, B.; Li, S.M.; Kemner, K.M.; et al. Protein oxidation implicated as the primary determinant of bacterial radioresistance. PLoS Biol. 2007, 5, e92. [CrossRef] [PubMed]

21. Makarova, K.S.; Omelchenko, M.V.; Gaidamakova, E.K.; Matrosova, V.Y.; Vasilenko, A.; Zhai, M.; Lapidus, A.; Copeland, A.; Kim, E.; Land, M.; et al. Deinococcus geothermalis: The pool of extreme radiation resistance genes shrinks. PLoS ONE 2007, 2, e955. [CrossRef] [PubMed]

22. Griffiths, E.; Gupta, R.S. Identification of signature proteins that are distinctive of the Deinococcus-Thermus phylum. Int. Microbiol. 2007, 10, 201-208. [PubMed]

23. De Groot, A.; Dulermo, R.; Ortet, P.; Blanchard, L.; Guerin, P.; Fernandez, B.; Vacherie, B.; Dossat, C.; Jolivet, E.; Siguier, P.; et al. Alliance of proteomics and genomics to unravel the specificities of Sahara bacterium Deinococcus deserti. PLoS Genet. 2009, 5, e1000434. [CrossRef] [PubMed]

24. Norais, C.A.; Chitteni-Pattu, S.; Wood, E.A.; Inman, R.B.; Cox, M.M. DdrB protein, an alternative Deinococcus radiodurans SSB induced by ionizing radiation. J. Biol. Chem. 2009, 284, 21402-21411. [CrossRef] [PubMed]

25. Sugiman-Marangos, S.N.; Weiss, Y.M.; Junop, M.S. Mechanism for accurate, protein-assisted DNA annealing by Deinococcus radiodurans DdrB. Proc. Natl. Acad. Sci. USA 2016, 113, 4308-4313. [CrossRef] [PubMed]

26. Kota, S.; Charaka, V.K.; Misra, H.S. PprA, a pleiotropic protein for radioresistance, works through DNA gyrase and shows cellular dynamics during postirradiation recovery in Deinococcus radiodurans. J. Genet. 2014, 93, 349-354. [CrossRef] [PubMed] 
27. Selvam, K.; Duncan, J.R.; Tanaka, M.; Battista, J.R. DdrA, DdrD and PprA: Components of UV and mitomycin C resistance in Deinococcus radiodurans R1. PLoS ONE 2013, 8, e69007. [CrossRef] [PubMed]

28. Ghosal, D.; Omelchenko, M.V.; Gaidamakova, E.K.; Matrosova, V.Y.; Vasilenko, A.; Venkateswaran, A.; Zhai, M.; Kostandarithes, H.M.; Brim, H.; Makarova, K.S.; et al. How radiation kills cells: Survival of Deinococcus radiodurans and Shewanella oneidensis under oxidative stress. FEMS Microbiol. Rev. 2005, 29, 361-375. [PubMed]

29. Du, J.; Gebicki, J.M. Proteins are major initial cell targets of hydroxyl free radicals. Int. J. Biochem. Cell Biol. 2004, 36, 2334-2343. [CrossRef] [PubMed]

30. Ezraty, B.; Gennaris, A.; Barras, F.; Collet, J.F. Oxidative stress, protein damage and repair in bacteria. Nat. Rev. Microbiol. 2017, 15, 385-396. [CrossRef] [PubMed]

31. Imlay, J.A.; Linn, S. DNA damage and oxygen radical toxicity. Science 1988, 240, 1302-1309. [CrossRef] [PubMed]

32. Sharma, A.; Gaidamakova, E.K.; Grichenko, O.; Matrosova, V.Y.; Hoeke, V.; Klimenkova, P.; Conze, I.H.; Volpe, R.P.; Tkavc, R.; Gostinčar, C.; et al. Across the tree of life, radiation resistance is governed by antioxidant $\mathrm{Mn}(2+)$, gauged by paramagnetic resonance. Proc. Natl. Acad. Sci. USA 2017, 114, E9253-E9260. [CrossRef] [PubMed]

33. Daly, M.J.; Gaidamakova, E.K.; Matrosova, V.Y.; Kiang, J.G.; Fukumoto, R.; Lee, D.Y.; Wehr, N.B.; Viteri, G.A.; Berlett, B.S.; Levine, R.L. Small-molecule antioxidant proteome-shields in Deinococcus radiodurans. PLoS ONE 2010, 5, e12570. [CrossRef] [PubMed]

34. Daly, M.J.; Gaidamakova, E.K.; Matrosova, V.Y.; Vasilenko, A.; Zhai, M.; Venkateswaran, A.; Wehr, N.B.; Viteri, G.A.; Berlett, B.S.; Levine, R.L. Accumulation of $\mathrm{Mn}(\mathrm{II})$ in Deinococcus radiodurans facilitates gamma-radiation resistance. Science 2004, 306, 1025-1028. [CrossRef] [PubMed]

35. Shashidhar, R.; Kumar, S.A.; Misra, H.S.; Bandekar, J.R. Evaluation of the role of enzymatic and nonenzymatic antioxidant systems in the radiation resistance of Deinococcus. Can. J. Microbiol. 2010, 56, 195-201. [CrossRef] [PubMed]

36. Griffiths, E.; Gupta, R.S. Distinctive protein signatures provide molecular markers and evidence for the monophyletic nature of the Deinococcus-Thermus phylum. J. Bacteriol. 2004, 186, 3097-3107. [CrossRef] [PubMed]

37. Akiva, E.; Itzhaki, Z.; Margalit, H. Built-in loops allow versatility in domain-domain interactions: Lessons from self-interacting domains. Proc. Natl. Acad. Sci. USA 2008, 105, 13292-13297. [CrossRef] [PubMed]

38. Singh, B.; Gupta, R.S. Conserved inserts in the Hsp60 (GroEL) and Hsp70 (DnaK) proteins are essential for cellular growth. Mol. Genet. Genom. 2009, 281, 361-373. [CrossRef] [PubMed]

39. Gupta, R.S.; Nanda, A.; Khadka, B. Novel molecular, structural and evolutionary characteristics of the phosphoketolases from bifidobacteria and Coriobacteriales. PLoS ONE 2017, 12, e0172176. [CrossRef] [PubMed]

40. Hashimoto, K.; Panchenko, A.R. Mechanisms of protein oligomerization, the critical role of insertions and deletions in maintaining different oligomeric states. Proc. Natl. Acad. Sci. USA 2010, 107, 20352-20357. [CrossRef] [PubMed]

41. Chandra, G.; Chater, K.F. Developmental biology of Streptomyces from the perspective of 100 actinobacterial genome sequences. FEMS Microbiol. Rev. 2014, 38, 345-379. [CrossRef] [PubMed]

42. Ricci, D.P.; Melfi, M.D.; Lasker, K.; Dill, D.L.; McAdams, H.H.; Shapiro, L. Cell cycle progression in Caulobacter requires a nucleoid-associated protein with high AT sequence recognition. Proc. Natl. Acad. Sci. USA 2016, 113, E5952-E5961. [CrossRef] [PubMed]

43. Lorenzini, E.; Singer, A.; Singh, B.; Lam, R.; Skarina, T.; Chirgadze, N.Y.; Savchenko, A.; Gupta, R.S. Structure and protein-protein interaction studies on Chlamydia trachomatis protein CT670 (YscO Homolog). J. Bacteriol. 2010, 192, 2746-2756. [CrossRef] [PubMed]

44. Sugiman-Marangos, S.N.; Peel, J.K.; Weiss, Y.M.; Ghirlando, R.; Junop, M.S. Crystal structure of the DdrB/ssDNA complex from Deinococcus radiodurans reveals a DNA binding surface involving higher-order oligomeric states. Nucleic Acids Res. 2013, 41, 9934-9944. [CrossRef] [PubMed]

45. Harris, D.R.; Tanaka, M.; Saveliev, S.V.; Jolivet, E.; Earl, A.M.; Cox, M.M.; Battista, J.R. Preserving genome integrity: The DdrA protein of Deinococcus radiodurans R1. PLoS Biol. 2004, 2, e304. [CrossRef] [PubMed]

46. Kota, S.; Misra, H.S. PprA: A protein implicated in radioresistance of Deinococcus radiodurans stimulates catalase activity in Escherichia coli. Appl. Microbiol. Biotechnol. 2006, 72, 790-796. [CrossRef] [PubMed] 
47. Truglio, J.J.; Croteau, D.L.; Van Houten, B.; Kisker, C. Prokaryotic nucleotide excision repair: The UvrABC system. Chem. Rev. 2006, 106, 233-252. [CrossRef] [PubMed]

48. Petit, C.; Sancar, A. Nucleotide excision repair: From E. coli to man. Biochimie 1999, 81, 15-25. [CrossRef]

49. Evans, D.M.; Moseley, B.E. Roles of the $u v s C, u v s D$, $u v s E$, and $m t c A$ genes in the two pyrimidine dimer excision repair pathways of Deinococcus radiodurans. J. Bacteriol. 1983, 156, 576-583. [PubMed]

50. Inaba, K.; Ito, K. Structure and mechanisms of the DsbB-DsbA disulfide bond generation machine. Biochim. Biophys. Acta 2008, 1783, 520-529. [CrossRef] [PubMed]

51. Shouldice, S.R.; Heras, B.; Walden, P.M.; Totsika, M.; Schembri, M.A.; Martin, J.L. Structure and function of DsbA, a key bacterial oxidative folding catalyst. Antioxid. Redox Signal. 2011, 14, 1729-1760. [CrossRef] [PubMed]

52. Dutton, R.J.; Boyd, D.; Berkmen, M.; Beckwith, J. Bacterial species exhibit diversity in their mechanisms and capacity for protein disulfide bond formation. Proc. Natl. Acad. Sci. USA 2008, 105, 11933-11938. [CrossRef] [PubMed]

53. Marino, S.M.; Gladyshev, V.N. Analysis and functional prediction of reactive cysteine residues. J. Biol. Chem. 2012, 287, 4419-4425. [CrossRef] [PubMed]

54. Wang, J.; Mueller, K.L.; Grossman, L. A mutational study of the C-terminal zinc-finger motif of the Escherichia coli UvrA protein. J. Biol. Chem. 1994, 269, 10771-10775. [PubMed]

55. Pakotiprapha, D.; Inuzuka, Y.; Bowman, B.R.; Moolenaar, G.F.; Goosen, N.; Jeruzalmi, D.; Verdine, G.L. Crystal structure of Bacillus stearothermophilus UvrA provides insight into ATP-modulated dimerization, UvrB interaction, and DNA binding. Mol. Cell 2008, 29, 122-133. [CrossRef] [PubMed]

56. Croteau, D.L.; DellaVecchia, M.J.; Wang, H.; Bienstock, R.J.; Melton, M.A.; Van Houten, B. The C-terminal zinc finger of UvrA does not bind DNA directly but regulates damage-specific DNA binding. J. Biol. Chem. 2006, 281, 26370-26381. [CrossRef] [PubMed]

57. Gupta, R.S. Identification of Conserved Indels that are Useful for Classification and Evolutionary Studies. In Bacterial Taxonomy, Methods in Microbiology Volume 41; Goodfellow, M., Sutcliffe, I.C., Chun, J., Eds.; Elsevier: London, UK, 2014; pp. 153-182.

58. Altschul, S.F.; Madden, T.L.; Schaffer, A.A.; Zhang, J.; Zhang, Z.; Miller, W.; Lipman, D.J. Gapped BLAST and PSI-BLAST: A new generation of protein database search programs. Nucleic Acids Res. 1997, 25, 3389-3402. [CrossRef] [PubMed]

59. White, O.; Eisen, J.A.; Heidelberg, J.F.; Hickey, E.K.; Peterson, J.D.; Dodson, R.J.; Haft, D.H.; Gwinn, M.L.; Nelson, W.C.; Richardson, D.L.; et al. Genome sequence of the radioresistant bacterium Deinococcus radiodurans R1. Science 1999, 286, 1571-1577. [CrossRef] [PubMed]

60. Jeanmougin, F.; Thompson, J.D.; Gouy, M.; Higgins, D.G.; Gibson, T.J. Multiple sequence alignment with Clustal X. Trends Biochem. Sci. 1998, 23, 403-405. [CrossRef]

61. Szklarczyk, D.; Franceschini, A.; Wyder, S.; Forslund, K.; Heller, D.; Huerta-Cepas, J.; Simonovic, M.; Roth, A.; Santos, A.; Tsafou, K.P.; et al. STRING v10: Protein-protein interaction networks, integrated over the tree of life. Nucleic Acids Res. 2015, 43, D447-D452. [CrossRef] [PubMed]

62. Von Mering, C.; Jensen, L.J.; Snel, B.; Hooper, S.D.; Krupp, M.; Foglierini, M.; Jouffre, N.; Huynen, M.A.; Bork, P. STRING: Known and predicted protein-protein associations, integrated and transferred across organisms. Nucleic Acids Res. 2005, 33, D433-D437. [CrossRef] [PubMed]

63. Sali, A.; Blundell, T.L. Comparative protein modelling by satisfaction of spatial restraints. J. Mol. Biol. 1993, 234, 779-815. [CrossRef] [PubMed]

64. Buchan, D.W.; Minneci, F.; Nugent, T.C.; Bryson, K.; Jones, D.T. Scalable web services for the PSIPRED Protein Analysis Workbench. Nucleic Acids Res. 2013, 41, W349-W357. [CrossRef] [PubMed]

65. Rose, P.W.; Prlic, A.; Bi, C.; Bluhm, W.F.; Christie, C.H.; Dutta, S.; Green, R.K.; Goodsell, D.S.; Westbrook, J.D.; Woo, J.; et al. The RCSB Protein Data Bank: Views of structural biology for basic and applied research and education. Nucleic Acids Res. 2015, 43, D345-D356. [CrossRef] [PubMed]

66. Pakotiprapha, D.; Samuels, M.; Shen, K.; Hu, J.H.; Jeruzalmi, D. Structure and mechanism of the UvrA-UvrB DNA damage sensor. Nat. Struct. Mol. Biol. 2012, 19, 291-298. [CrossRef] [PubMed]

67. Karakas, E.; Truglio, J.J.; Croteau, D.; Rhau, B.; Wang, L.; Van Houten, B.; Kisker, C. Structure of the C-terminal half of UvrC reveals an RNase H endonuclease domain with an Argonaute-like catalytic triad. EMBO J. 2007, 26, 613-622. [CrossRef] [PubMed] 
68. Meulenbroek, E.M.; Peron, C.C.; Jala, I.; Iwai, S.; Moolenaar, G.F.; Goosen, N.; Pannu, N.S. UV damage endonuclease employs a novel dual-dinucleotide flipping mechanism to recognize different DNA lesions. Nucleic Acids Res. 2013, 41, 1363-1371. [CrossRef] [PubMed]

69. Shen, M.Y.; Sali, A. Statistical potential for assessment and prediction of protein structures. Protein Sci. 2006, 15, 2507-2524. [CrossRef] [PubMed]

70. Xu, D.; Zhang, Y. Improving the physical realism and structural accuracy of protein models by a two-step atomic-level energy minimization. Biophys. J. 2011, 101, 2525-2534. [CrossRef] [PubMed]

71. Wiederstein, M.; Sippl, M.J. ProSA-web: Interactive web service for the recognition of errors in three-dimensional structures of proteins. Nucleic Acids Res. 2007, 35, W407-W410. [CrossRef] [PubMed]

72. Sippl, M.J. Recognition of errors in three-dimensional structures of proteins. Proteins 1993, 17, 355-362. [CrossRef] [PubMed]

73. Lovell, S.C.; Davis, I.W.; Arendall, W.B., III; de Bakker, P.I.; Word, J.M.; Prisant, M.G.; Richardson, J.S.; Richardson, D.C. Structure validation by Calpha geometry: phi, psi and Cbeta deviation. Proteins 2003, 50, 437-450. [CrossRef] [PubMed]

74. Colovos, C.; Yeates, T.O. Verification of protein structures: Patterns of nonbonded atomic interactions. Protein Sci. 1993, 2, 1511-1519. [CrossRef] [PubMed]

75. Eisenberg, D.; Luthy, R.; Bowie, J.U. VERIFY3D: Assessment of protein models with three-dimensional profiles. Methods Enzymol. 1997, 277, 396-404. [PubMed]

76. Benkert, P.; Tosatto, S.C.; Schomburg, D. QMEAN: A comprehensive scoring function for model quality assessment. Proteins 2008, 71, 261-277. [CrossRef] [PubMed]

77. Moseley, B.E.; Evans, D.M. Isolation and properties of strains of Micrococcus (Deinococcus) radiodurans unable to excise ultraviolet light-induced pyrimidine dimers from DNA: Evidence for two excision pathways. J. Gen. Microbiol. 1983, 129, 2437-2445. [CrossRef] [PubMed]

78. Stelter, M.; Acajjaoui, S.; McSweeney, S.; Timmins, J. Structural and mechanistic insight into DNA unwinding by Deinococcus radiodurans UvrD. PLoS ONE 2013, 8, e77364. [CrossRef] [PubMed]

79. Timmins, J.; Gordon, E.; Caria, S.; Leonard, G.; Acajjaoui, S.; Kuo, M.S.; Monchois, V.; McSweeney, S. Structural and mutational analyses of Deinococcus radiodurans UvrA2 provide insight into DNA binding and damage recognition by UvrAs. Structure 2009, 17, 547-558. [CrossRef] [PubMed]

80. Tanaka, M.; Narumi, I.; Funayama, T.; Kikuchi, M.; Watanabe, H.; Matsunaga, T.; Nikaido, O.; Yamamoto, K. Characterization of pathways dependent on the $u v s E$, uvrA1, or $u v r A 2$ gene product for UV resistance in Deinococcus radiodurans. J. Bacteriol. 2005, 187, 3693-3697. [CrossRef] [PubMed]

81. Dam, P.; Olman, V.; Harris, K.; Su, Z.; Xu, Y. Operon prediction using both genome-specific and general genomic information. Nucleic Acids Res. 2007, 35, 288-298. [CrossRef] [PubMed]

82. Moreno-Hagelsieb, G. The power of operon rearrangements for predicting functional associations. Comput. Struct. Biotechnol. J. 2015, 13, 402-406. [CrossRef] [PubMed]

83. Mao, X.; Ma, Q.; Zhou, C.; Chen, X.; Zhang, H.; Yang, J.; Mao, F.; Lai, W.; Xu, Y. DOOR 2.0: Presenting operons and their functions through dynamic and integrated views. Nucleic Acids Res. 2014, 42, D654-D659. [CrossRef] [PubMed]

84. Dandekar, T.; Snel, B.; Huynen, M.; Bork, P. Conservation of gene order: A fingerprint of proteins that physically interact. Trends Biochem. Sci. 1998, 23, 324-328. [CrossRef]

85. Overbeek, R.; Fonstein, M.; D'Souza, M.; Pusch, G.D.; Maltsev, N. The use of gene clusters to infer functional coupling. Proc. Natl. Acad. Sci. USA 1999, 96, 2896-2901. [CrossRef] [PubMed]

86. Inaba, K.; Murakami, S.; Suzuki, M.; Nakagawa, A.; Yamashita, E.; Okada, K.; Ito, K. Crystal structure of the DsbB-DsbA complex reveals a mechanism of disulfide bond generation. Cell 2006, 127, 789-801. [CrossRef] [PubMed]

87. Jaciuk, M.; Nowak, E.; Skowronek, K.; Tanska, A.; Nowotny, M. Structure of UvrA nucleotide excision repair protein in complex with modified DNA. Nat. Struct. Mol. Biol. 2011, 18, 191-197. [CrossRef] [PubMed]

88. Wagner, K.; Moolenaar, G.F.; Goosen, N. Role of the insertion domain and the zinc-finger motif of Escherichia coli UvrA in damage recognition and ATP hydrolysis. DNA Repair 2011, 10, 483-496. [CrossRef] [PubMed]

89. Radman, M. Protein damage, radiation sensitivity and aging. DNA Repair 2016, 44, 186-192. [CrossRef] [PubMed] 
90. Schoeffler, A.J.; May, A.P.; Berger, J.M. A domain insertion in Escherichia coli GyrB adopts a novel fold that plays a critical role in gyrase function. Nucleic Acids Res. 2010, 38, 7830-7844. [CrossRef] [PubMed]

91. Cumming, R.C.; Andon, N.L.; Haynes, P.A.; Park, M.; Fischer, W.H.; Schubert, D. Protein disulfide bond formation in the cytoplasm during oxidative stress. J. Biol. Chem. 2004, 279, 21749-21758. [CrossRef] [PubMed]

92. Imlay, J.A. How oxygen damages microbes: Oxygen tolerance and obligate anaerobiosis. Adv. Microb. Physiol. 2002, 46, 111-153. [PubMed]

93. Dean, C.J.; Alexander, P. Sensitization of radio-resistant bacteria to X-rays by iodoacetamide. Nature 1962, 196, 1324-1326. [CrossRef]

94. Dardalhon-Samsonoff, M.; Rebeyrotte, N. Role of DNA-membrane attachment in repair of radiation damage in Micrococcus radiodurans. Int. J. Radiat. Biol. Relat. Stud. Phys. Chem. Med. 1975, 27, 157-169. [CrossRef] [PubMed]

95. Vukovic-Nagy, B.; Fox, B.W.; Fox, M. The release of a deoxyribonucleic acid fragment after x-irradiation of Micrococcus radiodurans. Int. J. Radiat. Biol. Relat. Stud. Phys. Chem. Med. 1974, 25, 329-337. [CrossRef] [PubMed]

96. Duggan, D.E.; Anderson, A.W.; Elliker, P.R. Inactivation of the radiation-resistant spoilage bacterium Micrococcus radiodurans. II. Radiation inactivation rates as influenced by menstruum temperature, preirradiation heat treatment, and certain reducing agents. Appl. Microbiol. 1963, 11, 413-417. [PubMed]

97. Joe, M.H.; Jung, S.W.; Im, S.H.; Lim, S.Y.; Song, H.P.; Kwon, O.; Kim, D.H. Genome-wide response of Deinococcus radiodurans on cadmium toxicity. J. Microbiol. Biotechnol. 2011, 21, 438-447. [PubMed]

98. Burrell, A.D.; Feldschreiber, P.; Dean, C.J. DNA-membrane association and the repair of double breaks in x-irradiated Micrococcus radiodurans. Biochim. Biophys. Acta 1971, 247, 38-53. [CrossRef]

99. Driedger, A.A. Are there multiple attachments between bacterial DNA and the cell membrane? Can. J. Microbiol. 1970, 16, 881-882. [CrossRef] [PubMed]

100. Lin, C.G.; Kovalsky, O.; Grossman, L. DNA damage-dependent recruitment of nucleotide excision repair and transcription proteins to Escherichia coli inner membranes. Nucleic Acids Res. 1997, 25, 3151-3158. [CrossRef] [PubMed]

101. Ito, K.; Inaba, K. The disulfide bond formation (Dsb) system. Curr. Opin. Struct. Biol. 2008, 18, 450-458. [CrossRef] [PubMed]

102. Bardwell, J.C.; McGovern, K.; Beckwith, J. Identification of a protein required for disulfide bond formation in vivo. Cell 1991, 67, 581-589. [CrossRef]

103. Kojer, K.; Riemer, J. Balancing oxidative protein folding: The influences of reducing pathways on disulfide bond formation. Biochim. Biophys. Acta 2014, 1844, 1383-1390. [CrossRef] [PubMed]

104. Narumi, I.; Satoh, K.; Kikuchi, M.; Funayama, T.; Kitayama, S.; Yanagisawa, T.; Watanabe, H.; Yamamoto, K. Molecular analysis of the Deinococcus radiodurans recA locus and identification of a mutation site in a DNA repair-deficient mutant, rec30. Mutat. Res. 1999, 435, 233-243. [CrossRef]

105. Masure, H.R.; Pearce, B.J.; Shio, H.; Spellerberg, B. Membrane targeting of RecA during genetic transformation. Mol. Microbiol. 1998, 27, 845-852. [CrossRef] [PubMed]

106. Agostini, H.J.; Carroll, J.D.; Minton, K.W. Identification and characterization of uvrA, a DNA repair gene of Deinococcus radiodurans. J. Bacteriol. 1996, 178, 6759-6765. [CrossRef] [PubMed]

107. Lagkouvardos, I.; Jehl, M.A.; Rattei, T.; Horn, M. Signature protein of the PVC superphylum. Appl. Environ. Microbiol. 2014, 80, 440-445. [CrossRef] [PubMed]

(C) 2018 by the authors. Licensee MDPI, Basel, Switzerland. This article is an open access article distributed under the terms and conditions of the Creative Commons Attribution (CC BY) license (http:/ / creativecommons.org/licenses/by/4.0/). 